\title{
Recurrent Synoptic-Scale Rossby Wave Patterns and Their Effect on the Persistence of Cold and Hot Spells 0
}

\author{
MATTHIAS RÖTHLISBERGER ${ }^{\mathrm{a}}$ \\ Institute of Geography, and Oeschger Centre for Climate Change Research, University of Bern, Bern, Switzerland \\ LINDA FROSSARD \\ Institute of Geography, and Mobiliar Lab for Natural Risks, and Oeschger Centre for Climate Change Research, \\ University of Bern, Bern, Switzerland
}

\section{LANCE F. BOSART AND DANIEL KeySER}

Department of Atmospheric and Environmental Sciences, University at Albany, State University of New York, Albany, New York

\section{OLIVIA MARTIUS}

Institute of Geography, and Mobiliar Lab for Natural Risks, and Oeschger Centre for Climate Change Research, University of Bern, Bern, Switzerland

(Manuscript received 3 October 2018, in final form 6 March 2019)

\begin{abstract}
The persistence of surface weather during several recent high-impact weather events has been pivotal in generating their societal impact. Here we examine Hovmöller diagrams of the 250-hPa meridional wind during several periods with particularly persistent surface weather and find a common pattern in these Hovmöller diagrams. This pattern can be characterized as a "recurrent Rossby wave pattern" (RRWP), arising from multiple transient synoptic-scale wave packets. During such RRWP periods, individual troughs and ridges forming the wave packets repeatedly amplify in the same geographical region. We discuss the synoptic evolution of two RRWP periods, in February-March 1987 and July-August 1994, and illustrate how the recurrence of the transient wave packets led to unusually long-lasting cold and hot spells, which occurred simultaneously in several regions, each separated by roughly one synoptic wavelength. Furthermore, a simple index termed $R$ is proposed to identify RRWPs, which is based on both a time and wavenumber filter applied to conventional Hovmöller diagrams. A Weibull regression analysis then shows that large values of $R$ are statistically significantly linked to increased durations of winter cold and summer hot spells in large areas of the Northern Hemisphere midlatitudes. Traditionally, persistent high-impact surface weather has often been linked to the occurrence of proximate atmospheric blocking. In contrast to blocking, RRWPs affect persistent surface temperature anomalies over multiple synoptic wavelengths. We therefore argue that, in addition to blocking, RRWPs should be considered as an important flow feature leading to persistent high-impact surface weather.
\end{abstract}

Supplemental information related to this paper is available at the Journals Online website: https://doi.org/10.1175/JCLI-D-180664.s1.

\footnotetext{
${ }^{a}$ Current affiliation: Institute for Atmospheric and Climate Science, ETH Zürich, Zürich, Switzerland.
}

Corresponding author: Matthias Röthlisberger, matthias.roethlisberger@env.ethz.ch

\section{Introduction}

Recent high-impact weather events such as the European heat wave in 2003, the Russian heat wave in 2010, and the 2013/14 cold winter in the U.S. Midwest have been associated with unusually persistent surface weather (Black et al. 2004; Dole et al. 2011; Palmer 2014; Davies 2015). Therefore, it has been recognized that in addition to the magnitude of a particular weather event, its persistence can also significantly contribute to the 
societal impact of the event (e.g., Davies 2015; Pfleiderer and Coumou 2018). For reliable predictions about future weather-related hazards, it is thus of foremost importance to understand the atmospheric dynamical mechanisms that generate persistent high-impact surface weather, especially in the context of potentially changing atmospheric circulation due to climate change (Horton et al. 2015; Hoskins and Woollings 2015). The purpose of this study is to illustrate one particular dynamical mechanism for invoking unusually persistent surface weather that appears to have been operating during several recent periods of persistent high-impact surface weather.

The midlatitude surface weather (and its variations on synoptic time scales) is dominated by frequent passages of upper-level synoptic-scale Rossby waves [troughs and ridges (e.g., Hovmöller 1949)], which propagate along the midlatitude waveguide (Hoskins et al. 1985; Hoskins and Ambrizzi 1993; Martius et al. 2010). Hereby upperlevel synoptic-scale Rossby waves steer and interact with surface cyclones and anticyclones and thus strongly affect where warm, cold, wet, and dry surface weather occurs. Therefore, an investigation of the atmospheric dynamical processes leading to unusually persistent surface weather must start at upper-levels and consider synoptic-scale waves.

Several dynamical mechanisms have been proposed that can foster persistent surface weather. Recent studies have hypothesized that Arctic amplification might lead to larger-amplitude and slower-moving Rossby waves and should thus favor particularly persistent highimpact surface weather (Liu et al. 2012; Francis and Vavrus 2012; Cohen et al. 2014; Francis and Vavrus 2015; Francis and Skific 2015). However, trends in wave amplitudes have been shown to be highly sensitive to the choice of wave-amplitude metric (Barnes 2013; Screen and Simmonds 2013), and other authors have questioned this effect of Arctic amplification based on theoretical arguments (Hoskins and Woollings 2015) and modeling studies (Hassanzadeh et al. 2014).

Nevertheless, in general it can be expected that persistent surface weather occurs more frequently when the individual synoptic-scale waves attain particularly large amplitudes, break, and hereby become quasi stationary, for example, during atmospheric blocking episodes (Altenhoff et al. 2008). It is therefore well documented that blocking fosters the occurrence of collocated hot extremes (Pfahl and Wernli 2012; Röthlisberger et al. 2016) and cold extremes downstream of the block (Sillmann et al. 2011; Buehler et al. 2011; Whan et al. 2016), which can be expected to be rather persistent because of the persistent upper-level flow configuration. Moreover, the effect of atmospheric blocking on unusually persistent high-impact surface weather has been illustrated for the recent extremely high-impact heat waves in Europe in 2003 (Black et al. 2004) and in western Russia in 2010 (Barriopedro et al. 2011; Dole et al. 2011).

A further mechanism that has been proposed to explain the occurrence of persistent high-impact surface weather is quasi-resonant amplification of synopticscale Rossby waves (Petoukhov et al. 2013; Coumou et al. 2014; Kornhuber et al. 2017). These authors have argued that when certain dynamical conditions on the nature of the midlatitude waveguide are fulfilled, synoptic-scale waves can resonate with planetary-scale stationary waves and hereby induce hemispheric persistent and large-amplitude synoptic-scale wave patterns. These patterns then lead to persistent and synchronized extreme heat, cold, and rain all over the midlatitudes (Coumou et al. 2014). The quasi-resonance mechanism is thought to be most active in summer (Coumou et al. 2014; Kornhuber et al. 2017).

However, the studies of Davies (2015) and Barton et al. (2016), and to some extent also Fragkoulidis et al. (2018), suggest that a further, perhaps simpler, mechanism exists by which synoptic-scale waves can foster unusually persistent surface weather. Barton et al. (2016) have investigated a period of temporally clustered precipitation extremes at the Alpine south side in fall 1993 and found that this clustering period was preceded by several recurrent transient wave packets. Hereby the word "recurrent" is used to indicate that the synoptic-scale troughs and ridges building up the wave packets repeatedly amplified at the same longitudes. Figure 1a shows the Hovmöller diagram of the 250-hPa meridional wind averaged between $35^{\circ}$ and $65^{\circ} \mathrm{N}$ [hereafter referred to as $v_{\mathrm{ma}}(\lambda, t)$ for longitude $\lambda$ and time $t$ ] for this period. At least six synoptic-scale Rossby wave packets crossed North America and the North Atlantic in a recurrent manner between 25 September and 15 October 1993 (Fig. 1a). A similar behavior of transient wave packets during the 2013/14 winter (e.g., 10-29 January 2014, Fig. 1b) has been described by Davies (2015), who concluded that the recurrence of the synoptic-scale wave packets directly accounted for the anomalous signals appearing in the seasonal mean fields. Moreover, Fragkoulidis et al. (2018) have recently hypothesized that a sequence of wave packets approaching western Russia in summer 2010 also played a role in fostering the persistent surface weather there.

Davies (2015), Barton et al. (2016), and Fragkoulidis et al. (2018) illustrate that unusually persistent surface weather can arise when the synoptic-scale wave packets are organized over time in such a way that individual troughs and ridges amplify repeatedly at the same 

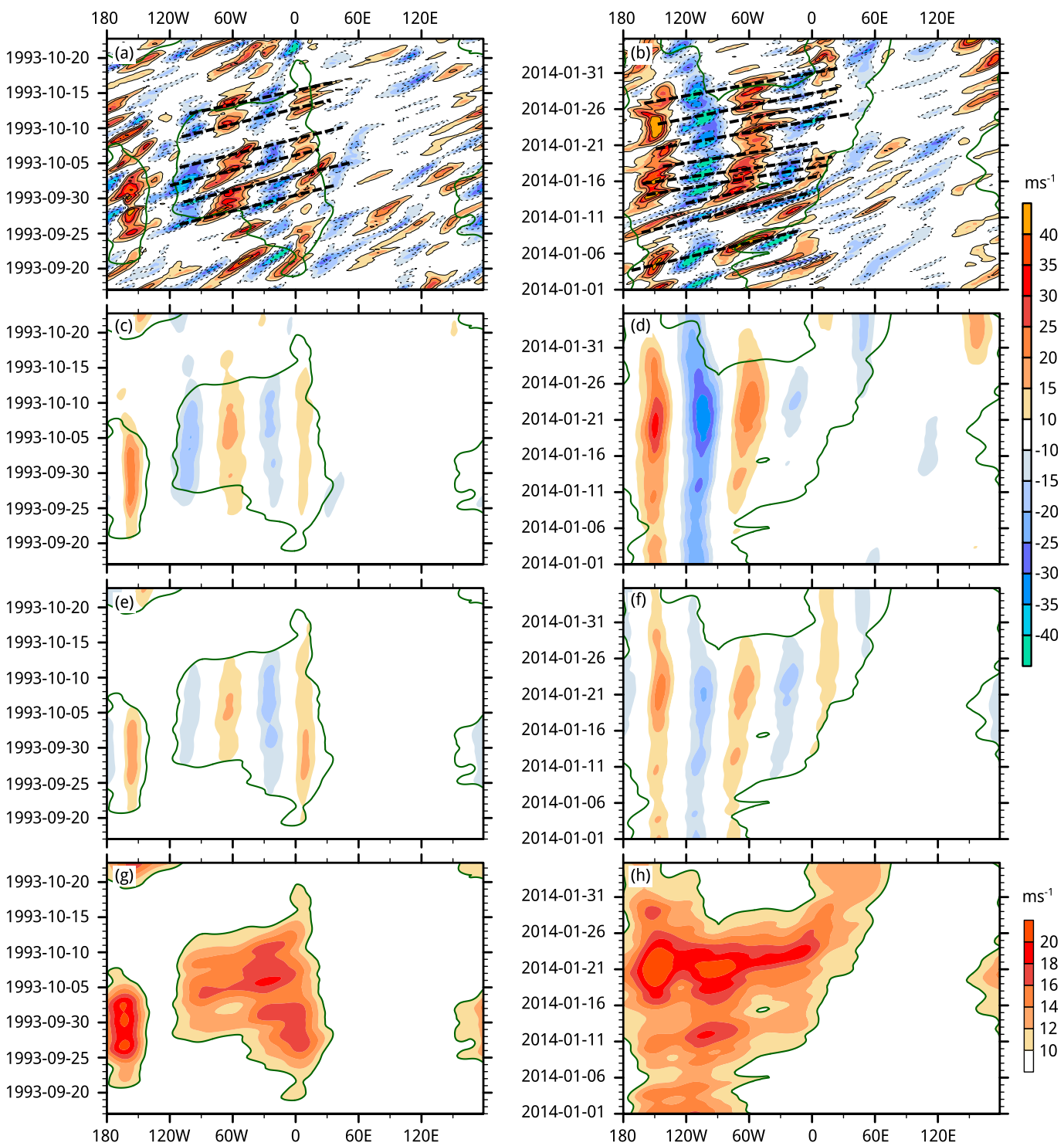

FIG. 1. Steps for computing the metric $R$ for the RRWPs (a),(c),(e),(g) in fall 1993 discussed by Barton et al. (2016) and (b),(d),(f),(h) in January 2014 discussed by Davies (2015). Hovmöller diagrams of (a),(b) 250-hPa meridional wind averaged between $35^{\circ}$ and $65^{\circ} \mathrm{N}\left(v_{\mathrm{ma}}\right)$, (c),(d) $v_{\mathrm{tf}}$, (e),(f) $v_{\mathrm{tf}, \mathrm{wnf}}$, and $(\mathrm{g})$, (h) the metric $R$. Green contours in all panels depict $R=10 \mathrm{~m} \mathrm{~s}^{-1}$. Black dashed lines in (a) and (b) show the approximate longitude-time trajectories of Rossby wave packets building up the respective RRWP.

longitudes. The recurrence of the synoptic-scale Rossby wave packets hereby continuously reinforces the synoptic-scale surface weather pattern such that it lasts much longer than typical synoptic time scales (approximately 2-7 days). From an impacts point of view, these recurrent Rossby wave patterns (RRWPs) therefore certainly merit consideration. However, to our knowledge, the existence of RRWPs and their effect on the persistence of surface weather has only been explicitly discussed in Davies (2015) and in Barton et al. (2016) on a case study basis only.
The aim of this study is to assess the effect of RRWPs on the persistence of cold and hot spells from a climatological point of view. To address this research goal we first discuss, based on RRWPs occurring in February-March 1987 and July-August 1994, how RRWPs can lead to persistent high-impact weather. Then we introduce a simple metric for identifying RRWPs and use this metric in combination with a Weibull regression to quantify the effect of RRWPs on the persistence of cold and hot spells climatologically. Finally, we discuss the relationship between atmospheric blocking and RRWPs. 
The remainder of this study is organized as follows: Sections $2 a$ and $2 b$ describe the dataset used for this study. Definitions of cold and hot spells and their respective climatologies are introduced in section $2 \mathrm{c}$. Then, in section $2 \mathrm{~d}$, a metric to identify RRWPs is proposed and in section 2e we introduce the statistical tools used for the climatological analysis. In section 3 the synoptic evolutions of two example cases of RRWPs leading to particularly long-lasting cold and hot spells are described. The climatological effect of RRWPs on cold and hot spell durations is discussed in section 4, before elaborating on the relationship between blocking and RRWPs in section 5. Finally, our key results are summarized in section 6 .

\section{Data and methods}

\section{a. ERA-Interim}

For all analyses in this study we use the ERA-Interim reanalysis dataset (Dee et al. 2011) for the period 19802015 with a 6-hourly temporal resolution. The dataset has a T255 spectral horizontal resolution and 60 hybrid $\sigma-p$ levels in the vertical, ranging from the surface to $0.1 \mathrm{hPa}$. The spacing of the 60 levels is described in Uppala et al. (2005). For this study, the data have been interpolated horizontally to a $1^{\circ} \times 1^{\circ}$ grid and vertically to pressure levels. All variables used here are freely available from the European Centre for MediumRange Weather Forecasts (ECMWF) homepage (http:// apps.ecmwf.int/datasets/data/interim-full-daily/levtype $=$ sfc/). Standardized 2-m temperature anomalies referred to below have been calculated using the local calendar time step mean and standard deviation.

\section{b. Blocking events}

To assess the relationship between atmospheric blocking and RRWPs, we use an updated version of the blocking algorithm of Schwierz et al. (2004), which identifies persistent negative anomalies in the 500-150$\mathrm{hPa}$ vertically averaged potential vorticity (PV). Anomalies are calculated relative to the climatological 121 time steps (30.25 days) running mean centered on the time step of interest and smoothed with 48-h running mean filter. As in Croci-Maspoli et al. (2007) and Pfahl and Wernli (2012) blocking events are identified based on PV anomalies below a threshold of -1.3 PVU (1 PVU $\left.=10^{-6} \mathrm{~K} \mathrm{~kg}^{-1} \mathrm{~m}^{2} \mathrm{~s}^{-1}\right)$, that can be tracked for at least five days and exhibit an areal overlap of more than $70 \%$ between consecutive time steps, such that $A_{t} \cap A_{t+6 h}>0.7 \times A_{t}$. Hereby, $A_{t}\left(A_{t+6 h}\right)$ is the area covered by the respective negative $\mathrm{PV}$ anomaly feature at time step $t(t+6 \mathrm{~h})$; see Rohrer et al. (2018) for a detailed description of the tracking algorithm. For each blocking event we identify its time of maximum amplitude as the time step at which the most negative PV anomaly value occurs within the blocking area.

\section{c. Cold and hot spells}

To characterize the persistence of sensible surface weather we identify cold and hot spells at each grid point between $20^{\circ}$ and $70^{\circ} \mathrm{N}$ in the ERA-Interim dataset based on 6-hourly 2-m temperatures for the period 1980-2015 in the following way. First, a linear trend is removed at each grid point. Second, for each 6-hourly calendar time step the 15th and 85th percentiles are calculated at each grid point and used to identify moderately cold and hot time steps. Hereby, all data from leap days are discarded. Third, consecutive time steps of moderately low or high temperatures are identified as uninterrupted cold and hot spells. Finally, cold (hot) spells separated by up to one day (i.e., four time steps) are merged by making the interruption part of the merged spell.

The merging of spells separated by up to one day is motivated from an impacts point of view: Conceivably, a multiday cold or hot spell followed by one day of nearaverage temperatures, followed by another multiday spell has more societal impact than the same two spells separated by a few weeks. Naturally, the choice of one day as maximum allowed gap between uninterrupted spells is subjective. However, we have repeated our statistical analyses for maximum allowed gaps of zero and two days and found that our results remain qualitatively similar. From the resulting set of spells (with durations from $6 \mathrm{~h}$ up to several weeks) we discard spells with durations of less than $36 \mathrm{~h}$. This minimum duration threshold for cold and hot spells is lower than in other studies (e.g., Sillmann et al. 2013), as the statistical analysis presented below requires sufficiently large numbers of spells with a wide range of spell durations for yielding robust results. Note, however, that our statistical results are valid for any spell duration quantile and hence also for long-lasting spells.

Figures $2 \mathrm{a}$ and $2 \mathrm{~b}$ show the number of extended winter [November-April (NDJFMA)] cold spells and extended summer [May-October (MJJASO)] hot spells with a duration greater than or equal to $36 \mathrm{~h}$ at each grid point. The numbers of cold and hot spells exhibit large regional differences but exceed 250 in most places (Figs. 2a,b). For later comparison with spell durations occurring during RRWPs discussed in section 3, moderately extreme spell durations (95th percentile) are shown in Figs. 2c and 2d. The 95th percentiles for both cold and hot spell durations range from 5 days (e.g., along the East Coast of the United States for cold spells, Fig. 2c) to roughly two weeks (e.g., over the North Sea 

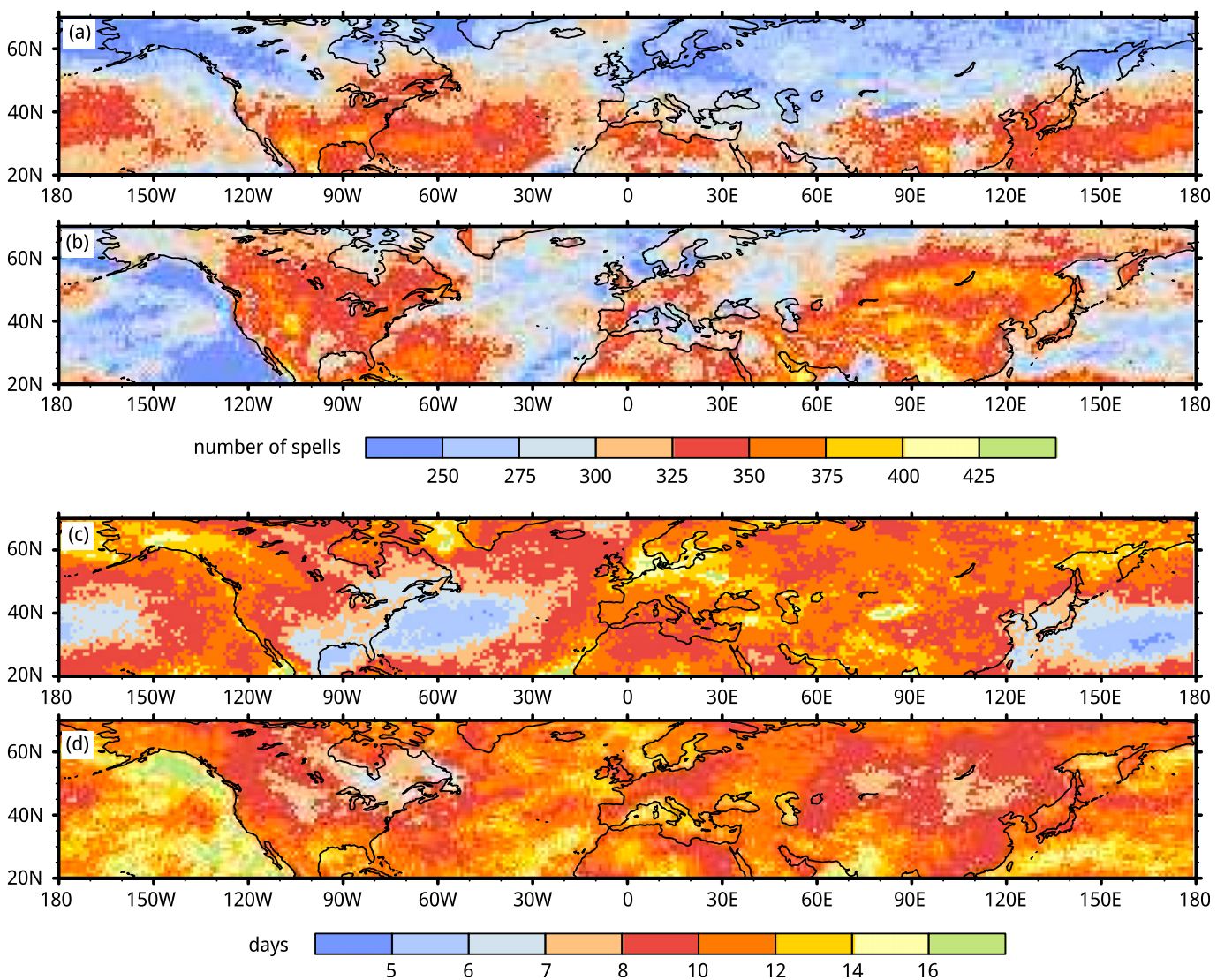

FIG. 2. Number of (a) NDJFMA cold spells and (b) MJJASO hot spells with a duration larger than or equal to $36 \mathrm{~h}$.

(c),(d) The 95th percentiles of (c) NDJFMA cold spell durations and (d) the MJJASO hot spell durations.

for hot spells, Fig. 2d). Overall there is a good agreement between the qualitative pattern in the moderately extreme spell durations shown here and the persistence metric introduced in Pfleiderer and Coumou (2018).

\section{d. The RRWP metric $R$}

To identify periods during which RRWP conditions occur, we propose a simple measure for the recurrence of synoptic-scale Rossby wave patterns, termed $R$. The metric $R$ is calculated from conventional Hovmöller diagrams of $v_{\mathrm{ma}}(\lambda, t)$ and its calculation is illustrated in Fig. 1 for the RRWP cases described by Barton et al. (2016) and Davies (2015).

The metric $R$ should attain large values whenever several synoptic-scale wave packets occur in a recurrent manner, so that they produce a synoptic wavenumber signal in the Hovmöller diagram of $v_{\text {ma }}$ that lasts for longer than synoptic time scales. In a first step we thus aim to identify signals that last for longer than synoptic time scales and apply a 14.25-day running mean (filter width corresponding to approximately two synopticscale Rossby wave periods, e.g., Chang and $\mathrm{Yu}$ 1999) to $v_{\text {ma }}(\lambda, t)$ to obtain a time-filtered version $v_{\text {tf }}(\lambda, t)$
(Figs. 1c,d). During times when the synoptic-scale waves do not amplify repeatedly in the same phase the time filter removes the synoptic wavenumber signals (see e.g., Figs. $1 \mathrm{a}, \mathrm{c}$ at $60^{\circ}-120^{\circ} \mathrm{E}$ during $20-30$ September). Large signals in $v_{\mathrm{tf}}(\lambda, t)$ could result either from stationary planetary-scale waves, recurrent synoptic-scale wave packets or persistent stationary synoptic-scale waves. Since we aim to identify signals from synoptic-scale waves only, we next filter $v_{\text {tf }}(\lambda, t)$ for synoptic (i.e., 4-15) wavenumber signals at each time step using a Fourier series decomposition over longitude and obtain a field $v_{\mathrm{t} f \mathrm{wnf}}(\lambda, t)$ of the synoptic wavenumber contribution to $v_{\mathrm{tf}}$. Finally, the metric $R(\lambda, t)$ is calculated for all longitudes $\lambda$ and time steps $t$ as the envelope of $v_{\mathrm{tf}, \mathrm{wnf}}(\lambda, t)$ (e.g., Zimin et al. 2003), that is,

$$
R(\lambda, t)=\left|2 \sum_{k=4}^{15} \hat{v}_{\mathrm{tf}}(k, t) e^{2 \pi i k l_{\lambda} / N}\right|,
$$

where $\hat{v}_{\mathrm{tf}}(k, t)$ is the Fourier coefficient of $v_{\mathrm{tf}}$ for wavenumber $k$ at time step $t, l_{\lambda}$ denotes the longitudinal gridpoint index for longitude $\lambda$ and $N=360$ is the number of longitudinal grid points. For the 
TABLE 1. Symbols for important quantities used in this study.

\begin{tabular}{lc}
\hline \hline Symbol & Definition \\
\hline$v_{\text {ma }}(\lambda, t)$ & $\begin{array}{c}\text { Meridional wind at } 250 \mathrm{hPa} \text { averaged between } 35^{\circ} \\
\text { and } 65^{\circ} \mathrm{N} .\end{array}$ \\
& Time-filtered $v_{\text {ma }}(\lambda, t)$, resulting from applying a \\
$v_{\mathrm{tf}}(\lambda, t)$ & 14.25 -day running mean to $v_{\mathrm{ma}}(\lambda, t)$. \\
& Synoptic wavenumber (4-15) contribution to \\
$v_{\mathrm{tf}, \mathrm{wnf}}(\lambda, t)$ & $v_{\mathrm{tf}}(\lambda, t)$. \\
$R(\lambda, t)$ & Envelope of the synoptic wavenumber contribution \\
& to $v_{\mathrm{tf}}(\lambda, t)$. \\
$R_{\mathrm{lon}}(\lambda, t)$ & $R(\lambda, t)$ longitudinally averaged in the sector \\
& $\left(\lambda-30^{\circ}, \lambda+30^{\circ}\right)$. \\
$\tilde{R}_{\lambda_{g}, i}$ & Representative $R$ value for $i$ th spell at grid point $g$, \\
& which has longitude $\lambda_{g}$. \\
$\exp \left(\alpha_{1}\right)$ & Exponentiated regression coefficient for $\tilde{R}$ \\
& (acceleration factor).
\end{tabular}

latitude-longitude grid used here $\left(1^{\circ}\right.$ resolution with longitude $\lambda$ ranging from $-180^{\circ}$ to $179^{\circ} \mathrm{E}$ ) the longitudinal gridpoint index is $l_{\lambda}=\lambda+180$. All the longitudetime quantities are summarized in Table 1 .

Based on the definition of $R$, it is possible that, besides recurrent Rossby wave packets, also persistent stationary synoptic-wavenumber waves could generate large values of $R$. Interestingly though, the climatological value of $R$ (Fig. 3a) exhibits clear longitudinally confined maxima in all seasons, just in the regions where transient synoptic-scale wave packets occur most frequently and attain largest amplitudes (Glatt and Wirth 2014; Souders et al. 2014b). These longitudinal variations in the mean $R$ value rule out hemispheric persistent stationary wave patterns as primary cause of large values of $R$ and clearly point to the relevance of synoptic-scale Rossby wave packets for generating large values of $R$.

Yet, also the troughs and ridges building up synopticscale Rossby wave packets can become stationary when the jet is sufficiently weak. However, according to linear Rossby wave theory, the group speed of a synoptic-scale Rossby wave packet always exceeds the phase speed of its individual wave crests, which is also seen very clearly in observations and models of various complexity (e.g., Lee and Held 1993; Wirth et al. 2018). Therefore, the group speed of a wave packet with stationary troughs and ridges is still positive, and, consequently, the individual troughs and ridges must decay when the wave packet envelope moves downstream (e.g., Lee and Held 1993; Wirth et al. 2018). Hence, it can be expected that in order to produce major $R$ features (lasting for up to several weeks), several Rossby wave packets with stationary troughs and ridges would have to occur in a recurrent manner. We argue that in such cases, the terminology "recurrent Rossby wave pattern" is still justified and we would like the metric $R$ to pick up such cases.
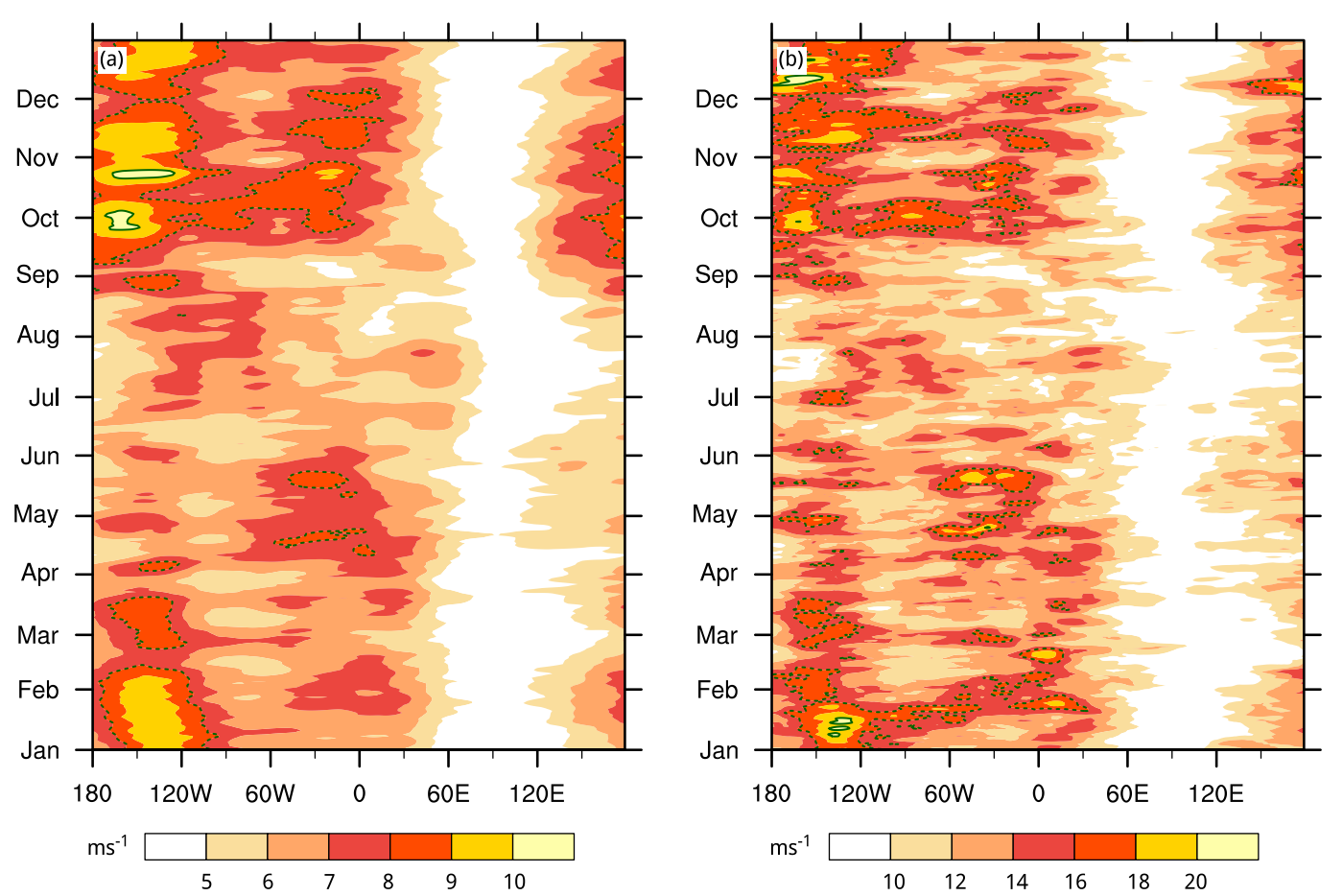

FIG. 3. (a) Climatological mean and (b) the 95th percentile of the metric $R$ at each longitude and calendar day. Green dashed and solid contours depict 8 and $10 \mathrm{~m} \mathrm{~s}^{-1}$ in (a) and 16 and $20 \mathrm{~m} \mathrm{~s}^{-1}$ in (b), respectively, for comparison with Figs. 4 and 8. 

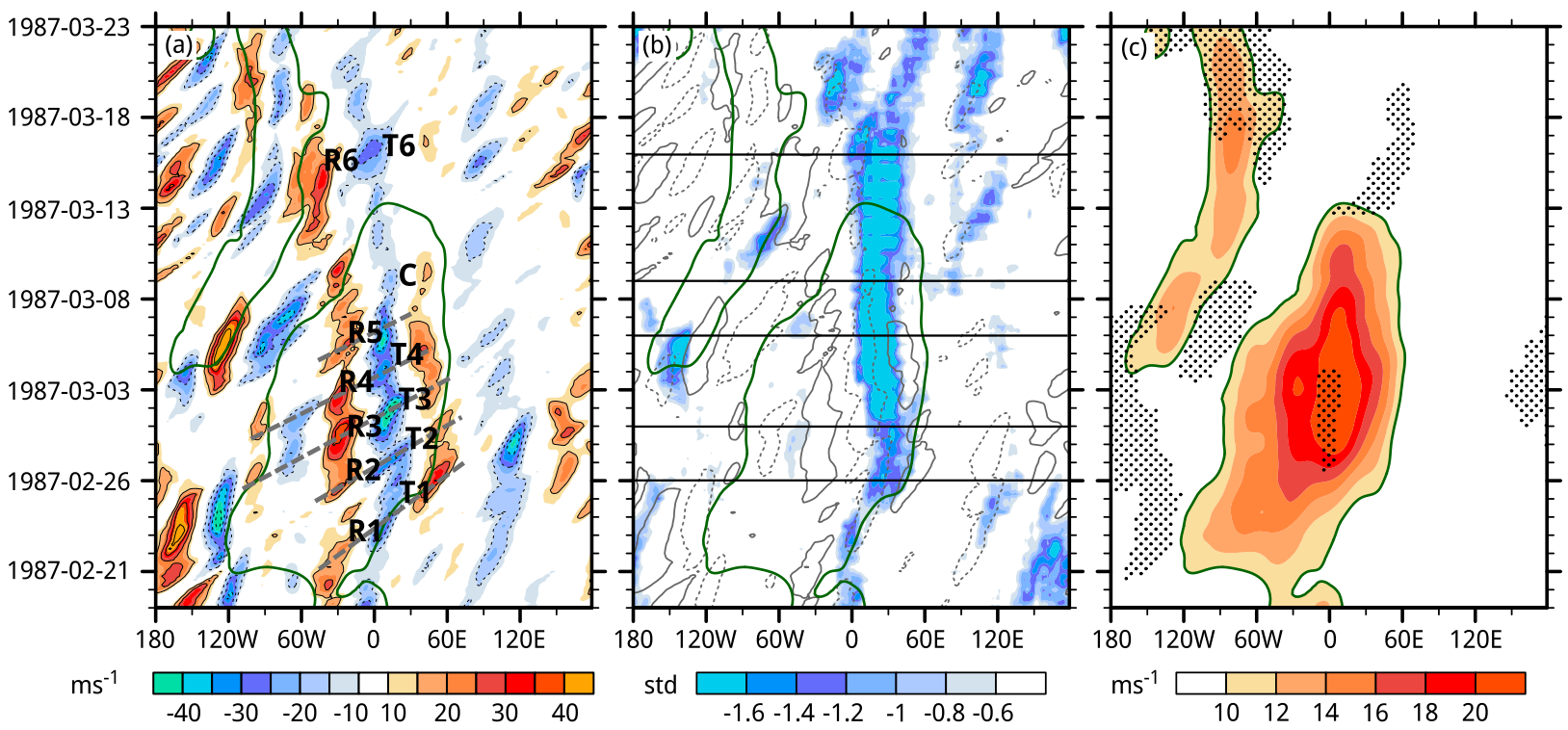

FIG. 4. Hovmöller diagrams of (a) $v_{\mathrm{ma}}$ at $250 \mathrm{hPa}$, (b) standardized 2-m temperature anomaly averaged between $35^{\circ}$ and $65^{\circ} \mathrm{N}$, and (c) $R$ for the RRWP in February-March 1987. Approximate longitude-time trajectories of the wave packets building up the RRWP are highlighted in (a) as dashed gray lines. Ridges and troughs over the eastern North Atlantic and Europe belonging to packets mentioned in the text are labeled as R1-R6 and T1-T4, and T6, respectively. The cutoff cyclone is indicated with the letter C. Horizontal lines in (b) indicate times for which fields are shown in Fig. 5. Dashed (solid) gray lines in (b) indicate $v_{\mathrm{ma}}$ at $250 \mathrm{hPa}$ of $-15(15) \mathrm{m} \mathrm{s}^{-1}$. Dotted areas in (c) show at which longitudes and times blocking is detected at least at one grid point between $0^{\circ}$ and $90^{\circ} \mathrm{N}$. The green solid contour in all panels shows $R=10 \mathrm{~m} \mathrm{~s}^{-1}$.

The ability of the metric $R$ for identifying RRWP conditions is illustrated exemplarily for the RRWPs discussed by Barton et al. (2016) and Davies (2015) in Figs. 1g and $1 \mathrm{~h}$. Large values of $R$ occur at longitudes and times where multiple synoptic-scale wave packets lead to a recurrent amplification of troughs and ridges.

Nevertheless, the fact that $R$ can contain contributions from persistent stationary hemispheric wave patterns should be regarded as a caveat of this metric. Moreover, in the case of just one unusually long lived and stationary Rossby wave packet, that is not preceded nor succeeded by another wave packet, our metric $R$ might attain considerable values for a few days, despite the lack of a recurrent wave pattern. An example of just one wave packet leading to increased $R$ values for a short period can be seen on Fig. 4a between 5 and 10 March at roughly $130^{\circ} \mathrm{W}$. However, despite these caveats, the cases presented in Figs. 1 and 4 (and Fig. 8), as well as numerous additional cases that we analyzed suggest that major $R$ features can be used as an indicator of where and when individual Rossby wave packets occur in a recurrent manner.

The climatological mean and the 95th percentile of $R$ at each longitude and calendar day are shown in Fig. 3. During fall and winter, largest values of both the mean and the 95th percentile of $R$ occur between $165^{\circ} \mathrm{E}$ and $120^{\circ} \mathrm{W}$, with largest mean values around $10 \mathrm{~m} \mathrm{~s}^{-1}$.
During spring, maxima in the mean $R$ are generally lower than in winter. Comparing Figs. 1g,h and Fig. 3b reveals that the $R$ values occurring during the RRWP cases in September-October 1993 and January 2014 were moderately extreme.

\section{e. Weibull regression}

In section 4 we test whether RRWP conditions (characterized by large values of $R$ ) are associated with a statistically significant increase in the duration of cold and hot spells during extended winter (NDJFMA) and summer (MJJASO), respectively. To do so we use a Weibull regression, which is mathematically slightly more complex than the well-known Gaussian linear regression model, but apart from that has the same role and very similar features as any other parametric regression model. This type of model is frequently used in health sciences to model the time until a certain event occurs as a function of one or multiple covariates (e.g., Hosmer et al. 2008; Kleinbaum and Klein 2012; Zhang 2016). In the health sciences context the time to event may be the time to death or remission of a patient after a medical treatment and the covariates could be the type of treatment (real treatment versus placebo) or the age of the patient. Here we fit a Weibull regression model to cold and hot spell durations at each grid point and include a measure of $R$ as covariate. The fitted Weibull 
model then allows to assess the effect of variations in $R$ (indicative of RRWPs) on the spell duration distribution at each grid point. Note, however, that regression models (including the Weibull model) do not prove any causality, but rather quantify interactions between covariates (in our case the measure of $R$ ) and the analyzed data (spell durations). The causality in our argumentation is based on the well-known meteorological fact that synoptic-scale Rossby waves have a direct effect on surface temperature and based on previous case studies (Davies 2015; Barton et al. 2016; Fragkoulidis et al. 2018). An introduction to the Weibull regression model is provided in the supplemental material. In this section we therefore only present the model set up and describe its utility for addressing the research question expressed in the first sentence of this paragraph.

Before using the metric $R$ as a covariate for the spell durations, it is necessary to attribute one representative value of $R$ to each spell. However, since spells last multiple time steps and $R$ is calculated at 6-hourly intervals, there is some ambiguity as to which $R$ value should be chosen as covariate. Moreover, the spell duration is conceivably affected by the Rossby wave pattern in a longitudinal sector around the grid point of consideration. Therefore, a representative value of $R$ should be based on some longitudinal averaging of $R$ around the grid point of consideration. Here we opt for the following procedure: At each longitude $\lambda$, we first average $R(\lambda, t)$ at each time $t$ in a longitudinal sector $\left(\lambda-30^{\circ}, \lambda+30^{\circ}\right)$ to obtain another longitude-time field $R_{\text {lon }}(\lambda, t)$ of longitudinally averaged $R$ values. For the $i$ th spell at grid point $g$ with longitude $\lambda_{g}$, we select the median value of $R_{\mathrm{lon}}\left(\lambda_{g}, t\right)$ over the spell duration $t_{g, i}^{\text {start }}$ to $t_{g, i}^{\text {end }}$ as its representative $R$ value (hereafter referred to as $\left.\tilde{R}_{\lambda_{g}, i}\right)$, that is,

$$
\tilde{R}_{\lambda_{g}, i}=\operatorname{median}\left\{R_{\mathrm{lon}}(\lambda, t), t=t_{g, i}^{\mathrm{start}}, \ldots, t_{g, i}^{\mathrm{end}}\right\} .
$$

At each grid point $g$ between $20^{\circ}$ and $70^{\circ} \mathrm{N}$, a Weibull regression model is fitted to the $n_{g}$ spell durations $D_{g, 1}, \ldots, D_{g, n_{g}}$ observed at this grid point. The model takes the form

$$
\begin{aligned}
\ln \left(D_{g, i}\right)= & \alpha_{0, g}+\alpha_{1, g} \tilde{R}_{\lambda_{g}, i}+\sum_{j=2}^{6} \alpha_{j, g} m_{j}\left(t_{g, i}^{\mathrm{start}}\right) \\
& +\sigma_{g} \varepsilon_{g, i}, i=1, \ldots, n_{g}
\end{aligned}
$$

where $\alpha_{0, g}, \ldots, \alpha_{6, g}$ are the regression coefficients, $\varepsilon_{g, 1}, \ldots, \varepsilon_{g, n_{g}}$ are error terms following the standard extreme minimum value distribution and $\sigma_{g}>0$ is a scale parameter. In addition to the RRWP metric $\tilde{R}$ we have also included covariates $m_{2}(\cdot), \ldots, m_{6}(\cdot)$ that are dummy variables for the months DJFMA (JJASO) in the models of cold (hot) spell durations, the months of November (May) being represented implicitly by the intercept. As indicated by Eq. (3), the month of the $i$ th spell at grid point $g$ is determined by its starting time $t_{g, i}^{\text {start }}$. We have included these dummy variables to account for possible monthly variations in the spell durations and $\tilde{R}$.

To fit this model at each grid point for cold and hot spells we follow exactly the procedure recommended in Zhang (2016) and use the same CRAN-R packages as Zhang (2016) for the model fitting and significance testing. From this procedure we obtain spatial fields of all regression coefficients $\alpha_{j}, j=0, \ldots, 6$, in Eq. (3) together with corresponding $p$ values. Statistical significance of a particular coefficient is then assessed by applying the false discovery rate (FDR) test of Benjamini and Hochberg (1995) with a maximum FDR of 0.1 to the respective field of $p$ values [see Ventura et al. (2004) and Wilks (2016) for further information on the use of the FDR test in atmospheric sciences].

In this paper, only the coefficients $\alpha_{1}$ will be discussed, which express the effect of $\tilde{R}$ on the spell durations. The value $\exp \left(\alpha_{1}\right)$ is a so-called acceleration factor (Hosmer et al. 2008; Zhang 2016) and corresponds to the factor of change in all quantiles of the spell duration $D$ per unit increase in $\tilde{R}$ (Hosmer et al. 2008). More generally, the Weibull model assumes that the spell durations are realizations of Weibull distributed random variables, each with a rate parameter $\theta$ that depends on the associated $\tilde{R}$ value. Thus, the spell durations $D_{g, i}$ follow different Weibull distributions with individual rate parameters $\theta_{g, i}$ for each spell and a common shape parameter $p_{g}$ for each grid point (see supplemental material).

The $q$-quantiles $d_{q, x}$ and $d_{q, x+n}$ of the spell duration distributions under model Eq. (3) for two different $\tilde{R}$ values $x$ and $x+n$, respectively, satisfy (see supplemental material for a derivation)

$$
\frac{d_{q, x+n}}{d_{q, x}}=\exp \left(\alpha_{1}\right)^{n} .
$$

This relation holds for any fixed probability $q$ and thus entails that every quantile of the spell durations is multiplied by the factor $\exp \left(\alpha_{1}\right)^{n}$ under an increase of $\tilde{R}$ by $n$ units. Hence, if, for example, $\exp \left(\alpha_{1, g}\right)=1.1$ for hot spells at a certain grid point $g$, then a $1 \mathrm{~m} \mathrm{~s}^{-1}\left(5 \mathrm{~m} \mathrm{~s}^{-1}\right)$ increase in $\tilde{R}_{\lambda_{g}}$ is associated with $1.1\left(1.1^{5}=1.61\right)$ times longer durations of the median, the 90th, and any other percentiles of the spell durations occurring under the increased $\tilde{R}_{\lambda_{g}}$ value. A highly beneficial property of the Weibull regression model is thus that it allows for making a statement about the effect of RRWPs on the entire distribution of the spell durations. Consequently, 
by using the Weibull regression model there is no need to subjectively define how long "significant" spell durations should be. The quality of the model fits is assessed at each grid point by applying the AndersonDarling goodness-of-fit test, following the recommendations of Littell et al. (1979) (see also online supplemental material).

\section{Two examples of RRWPs leading to unusually persistent surface weather}

\section{a. February and March 1987}

We first discuss an RRWP case that occurred during late February and the first half of March 1987 and led to extremely long-lasting cold spells over much of Europe. The Hovmöller diagram of $v_{\text {ma }}$ (Fig. 4a) shows a stationary synoptic-scale wave pattern (with a wavenumber of approximately 5 on 26 February, increasing to approximately wavenumber 6 on 5 March) that is, however, built up by a sequence of at least five distinct (synoptic scale) wave packets propagating across the North Atlantic between approximately 21 February and 10 March 1987. Note that the individual troughs and ridges building up these Rossby wave packets each have a phase speed $c>0$, and are thus not stationary (Fig. 4). The recurrent amplification of these synopticscale troughs and ridges first established and then reinforced the northerly flow over Europe (between $0^{\circ}$ and $30^{\circ} \mathrm{E}$ ). This led to very persistent cold conditions over large parts of Europe (Fig. 4b).

These wave packets were each in phase with one another over the entire eastern North Atlantic and Europe $\left(30^{\circ} \mathrm{W}-60^{\circ} \mathrm{E}\right)$ and thus large values of $R$ are found in the North Atlantic-European sector (Fig. 4c), with maximum values exceeding $16 \mathrm{~m} \mathrm{~s}^{-1}$ during 26 February11 March. After 11 March, the wavelength of the wave pattern over the North Atlantic increased and only one trough-ridge couplet covered the sector between $60^{\circ} \mathrm{W}$ and $60^{\circ} \mathrm{E}$ (Figs. $4 \mathrm{a}, 5 \mathrm{i}, \mathrm{j}$ ), which corresponds to a wavenumber 3 pattern and hence indicates amplified planetaryscale waves. Therefore, no large values of $R$ were recorded during this period over the North Atlantic.

The recurrence of the synoptic-scale waves during the period of 26 February-11 March is also clearly visible in upper-level weather maps (Fig. 5). At 0000 UTC 26 February, a trough was located over the western North Atlantic and a ridge covered the eastern North Atlantic (labeled R2 in Fig. 5a). Over Europe, an incipient trough (T2) was forming at the upstream flank of an older trough T1 (Fig. 5a). This wave pattern was associated with cold conditions over the central North Atlantic and northeastern Europe, where first cold spells started at this time (Fig. 6a). Over the central North
Atlantic, cold conditions had started already a few days earlier and by 26 February cold spell durations extended up to 6 days. On 1 March, a new ridge (R3) had formed over the eastern North Atlantic and a next trough (T3) was forming over Europe at the same longitude where $\mathrm{T} 2$ had formed three days earlier, while the trough T2 had moved northeastward (Fig. 5c). This ridge-trough pattern over the eastern North Atlantic and Europe reinforced the already preexisting surface temperature anomaly pattern (Fig. 5d) and prolonged the cold spells over northeastern Europe (Fig. 6c).

Moreover, from approximately 26 February to 3 March, synoptic-scale troughs and ridges amplified repeatedly at similar longitudes not only over the North Atlantic and Europe but also farther upstream, over North America and over the eastern North Pacific (Figs. 4a, 5a-d). This recurrence of the synoptic-scale waves led to persistent cold anomalies and prolonged cold spells also over the central North Atlantic and the southwestern United States and Mexico (Fig. 6c).

Over the eastern North Atlantic and Europe, yet another ridge-trough couplet (R5, T4) had amplified by 6 March, again at the same longitudes as their predecessor ridge-trough couplets and further prolonged the cold conditions in northeastern Europe (Figs. 5e,f, $6 e)$. At 0000 UTC 6 March the cold air outbreak associated with trough $\mathrm{T} 4$ reached France at its western boundary and northern Africa at its southern boundary (Fig. 5f). Trough T4 formed a cutoff low during the following days (labeled "C" in Figs. 4 and 5), and was reamplified by smaller-wavelength disturbances propagating across the North Atlantic between 8 and 11 March (Figs. 4a, 5g). Because of cold-air advection at the northern and western flank of the cutoff, the cold spells over Europe persisted further and by 9 March reached durations of up to two weeks (Fig. 6g). Finally, between 12 and 13 March the cutoff reattached to the main polar air mass (not shown) and by 13 March formed part of a large blocking pattern over Europe and western Russia, featuring anticyclones over the North Atlantic and western Russia, and a wavelength corresponding to roughly wavenumber 3 (Fig. 4a).

This wavenumber 3 ridge-trough pattern covered the longitude sector $60^{\circ} \mathrm{W}-60^{\circ} \mathrm{E}$ (labeled R6 and T6 in Fig. 5i) and persisted for several days longer and continuously fed the cold spells over Europe, which reached durations of up to 20 days in some areas of eastern Europe (Fig. 6i). Finally, on 18-19 March warmer air reached Europe from the North Atlantic and terminated the cold spells in most areas (not shown).

Troughs T1-T4 and ridges R1-R5 thus formed and decayed one after another at similar longitudes and thereby built up a persistent and stationary synoptic-wavenumber 

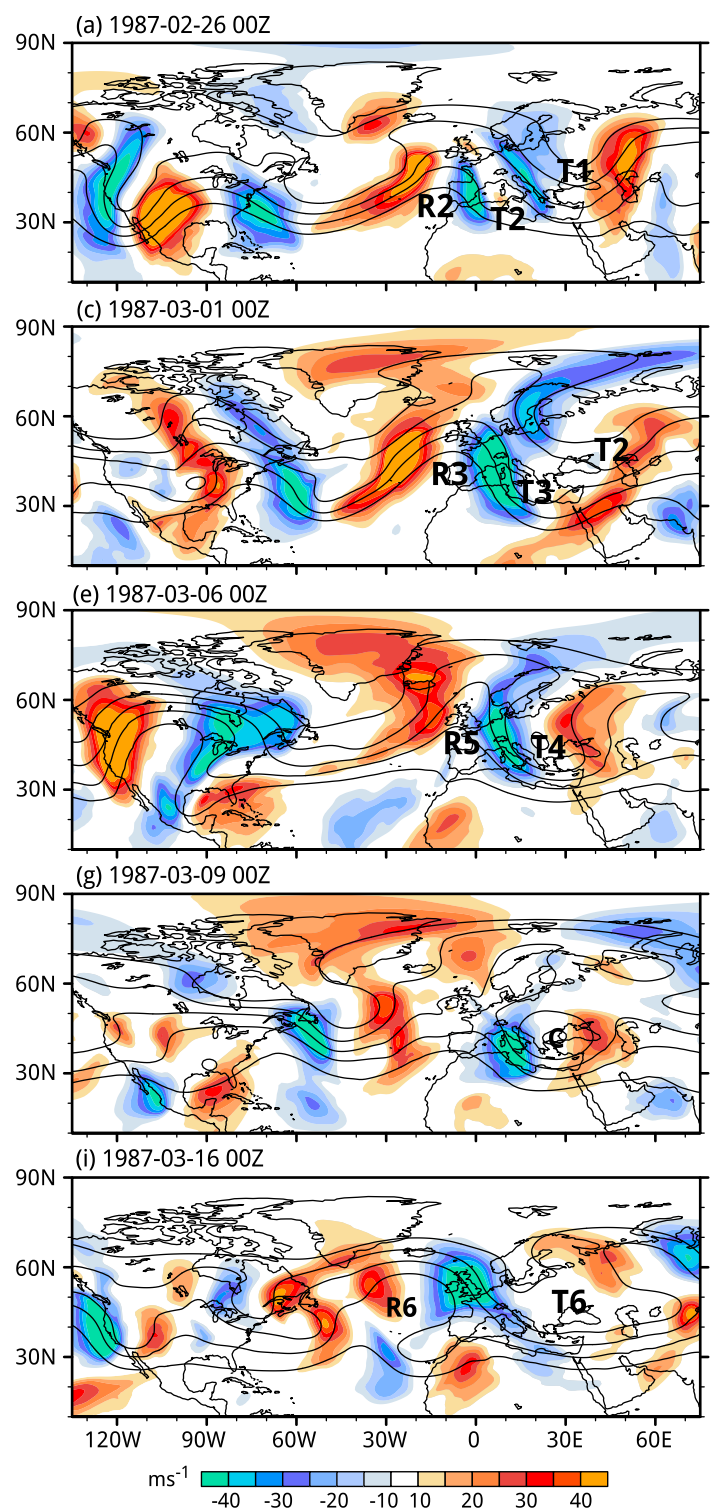

(b) $1987-02-2600 Z$

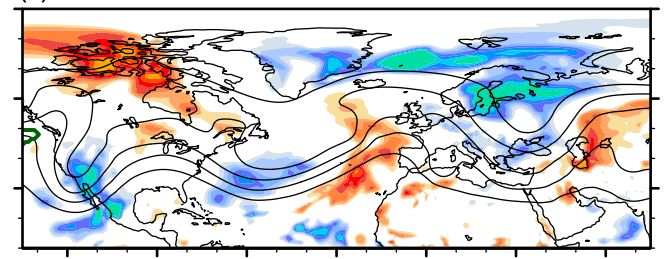

(d) 1987-03-01 00Z

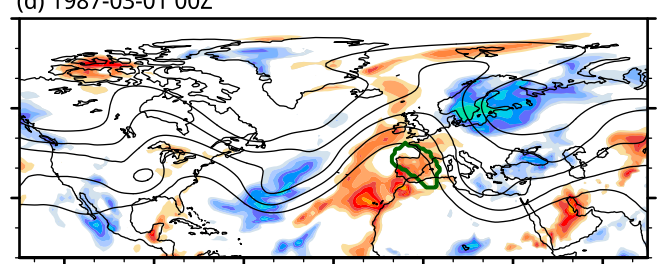

(f) 1987-03-06 00Z

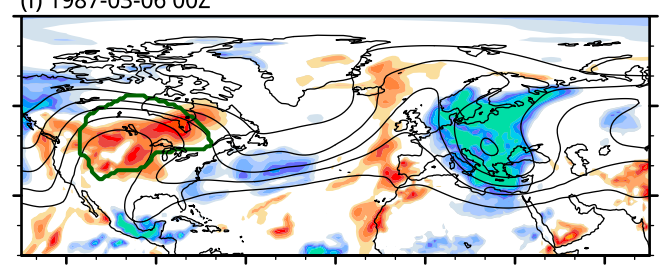

(h) 1987-03-09 00Z

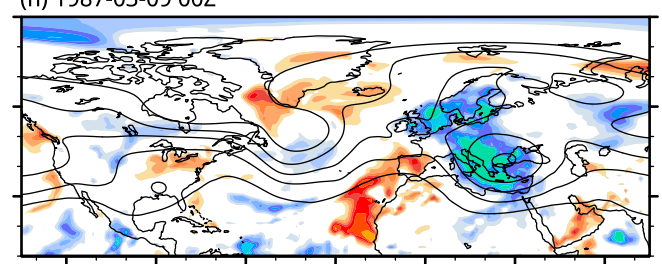

(j) 1987-03-16 00Z

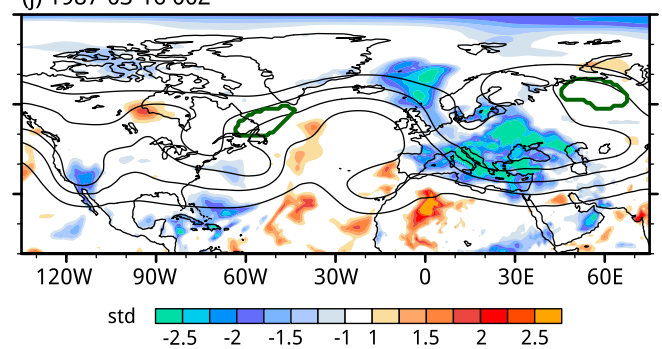

FIG. 5. (a),(c),(e),(g),(i) Meridional wind $v$ at $250 \mathrm{hPa}$ (shading), and (b),(d),(f),(h),(j) standardized 2-m temperature anomaly (shading). Black contours indicate 250-hPa geopotential height starting from 9800 to $10800 \mathrm{~m}$ in steps of $200 \mathrm{~m}$. Green contours in (b),(d),(f),(h),(j) show atmospheric blocking as defined in Schwierz et al. (2004). Ridges R1-R6 and troughs T1-T4 and T6 are labeled in (a),(c),(e),(g),(i).

signal in the Hovmöller diagram (Figs. 4a). However, these troughs and ridges were each distinct, nonstationary flow features, which can be seen from the pulse-like nature and the longitudinal propagation of the respective negative and positive signals in the Hovmöller diagram associated with these troughs and ridges (Fig. 4a). Figures 7a and 7c further illustrate exemplarily the nonstationary nature of ridges $\mathrm{R} 2$ and $\mathrm{R} 3$, and troughs $\mathrm{T} 1$ and $\mathrm{T} 3$. Clearly, the ridges $\mathrm{R} 2$ and R3 gradually build up at the upstream flank of the predecessor ridge and their peaks are not stationary.
Moreover, also troughs T1 and T3 amplify and propagate downstream, albeit with a lower phase speed than the ridges $\mathrm{R} 2$ and $\mathrm{R} 3$. The recurrence and propagation of troughs $\mathrm{T} 1$ and $\mathrm{T} 3$ (ridges R2 and R3) is contrasted by the persistent stationary (wavenumber 3 ) ridgetrough couplet R6 and T6 (Fig. 7e).

Furthermore, during the first week of this period the wave packets were in phase not only over the North Atlantic and Europe, but also across North America (Fig. 4a). Therefore, persistent cold anomalies were not only occurring in Europe, but rather in all places where 

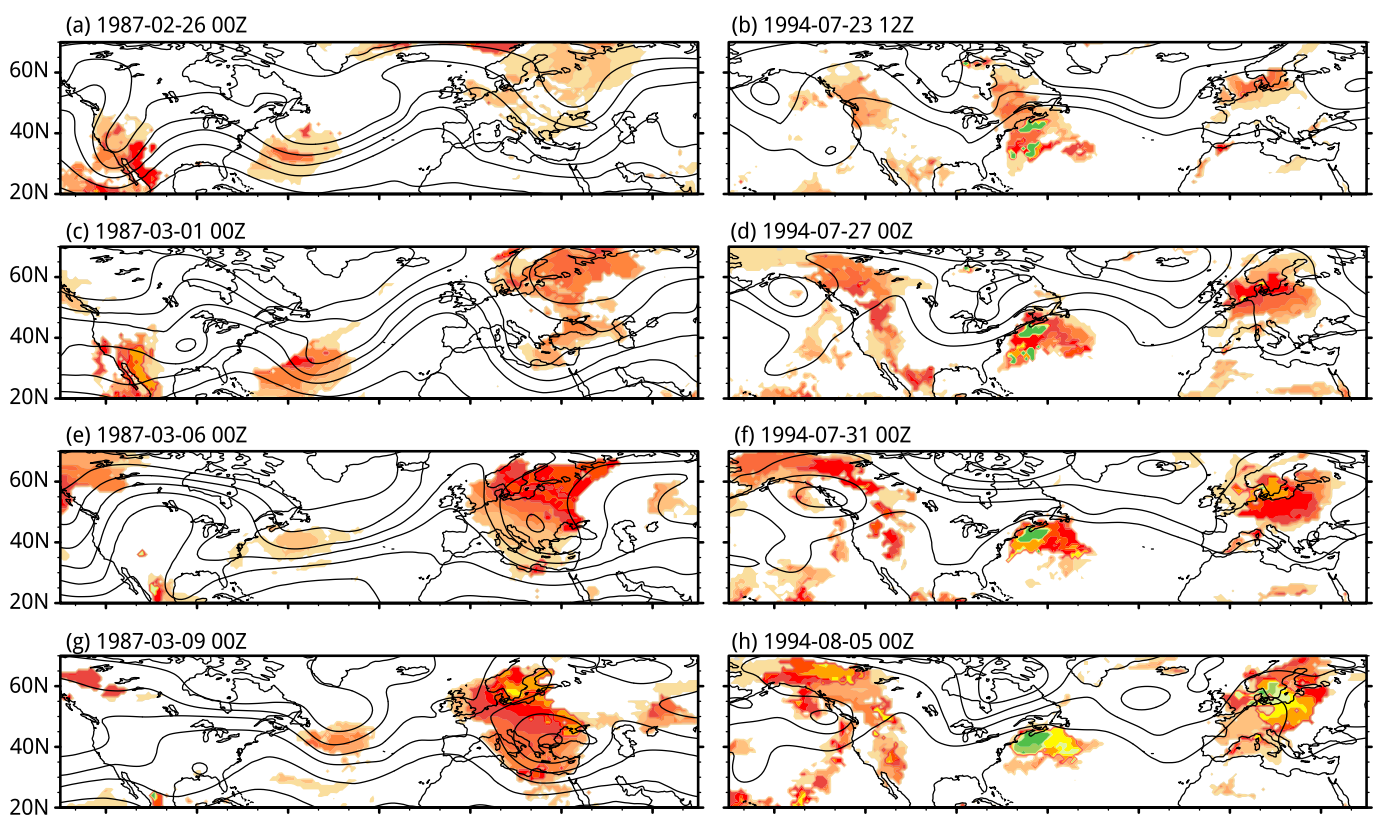

(h) 1994-08-05 00Z
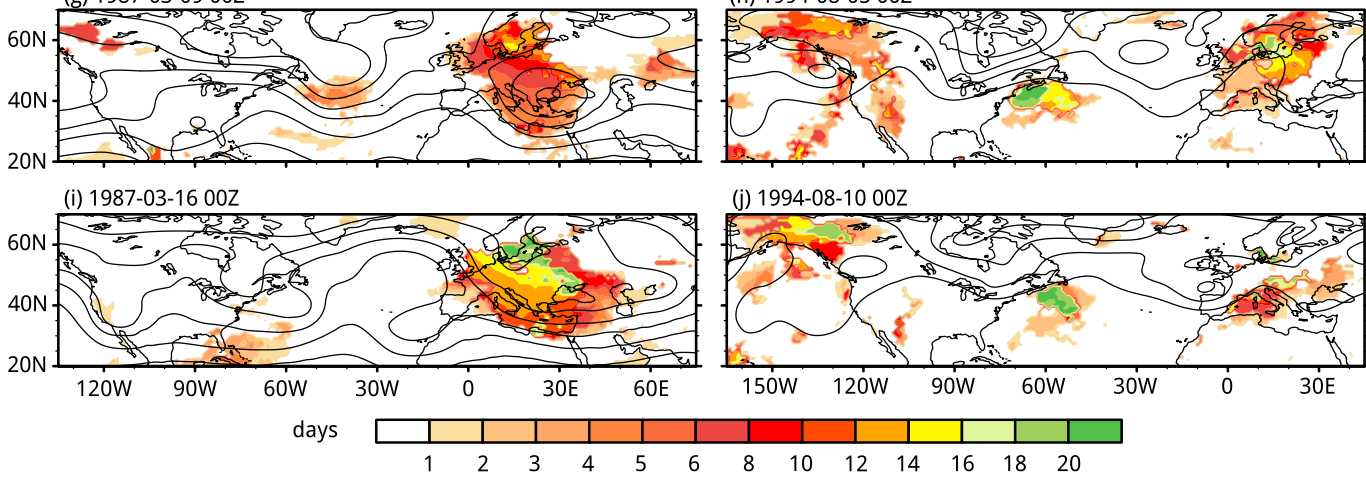

(j) 1994-08-10 00Z

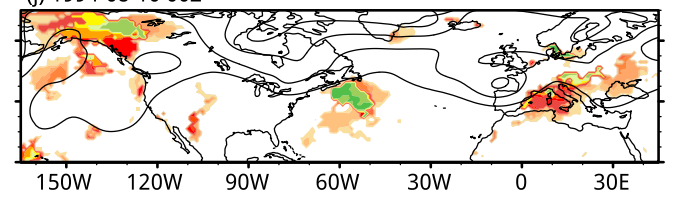

FIG. 6. (a),(c),(e),(g),(i) Cold spell duration (shading) for the 1987 case and (b),(d),(f),(h),(j) hot spell duration (shading) for the 1994 case. The dates depicted here are the same as in Figs. 5 and 9, respectively. Black contours indicate $250-\mathrm{hPa}$ geopotential height starting from 9800 to $10800 \mathrm{~m}$ in steps of $200 \mathrm{~m}$.

the recurrent wave pattern exhibited a trough. This illustrates that RRWPs can lead to simultaneous persistent high-impact surface weather over multiple synoptic wavelengths. This aspect of RRWPs is further discussed in the second case, which illustrates unusually persistent hot spells arising from an RRWP occurring during summer 1994.

\section{b. July and August 1994}

During late July and early August 1994 Europe experienced one of its most severe heat waves since 1950 (Russo et al. 2015). During this period several synopticscale Rossby wave packets (approximately wavenumber 6) amplified over the western North Pacific and propagated across North America and the North Atlantic into western Europe (Fig. 8a). Over the eastern North Pacific, North America, the North Atlantic, and western Europe the wave packets were in phase with their respective predecessor and successor wave packets (Fig. 8a), which led to large values of $R$ at these longitudes during the entire period (Fig. 8c). The recurrent southerly flow over western Europe and ridging over central Europe contributed to anomalously warm temperatures between $0^{\circ}$ and $30^{\circ} \mathrm{E}$ (Fig. 8b). Interestingly, during this period persistent warm anomalies occurred also at different longitudes, around $60^{\circ} \mathrm{W}, 120^{\circ} \mathrm{W}$, and $120^{\circ} \mathrm{E}$. We now briefly describe the synoptic evolution of this RRWP event over the North Atlantic and Europe.

On 23 July 1994 the large-scale flow over Europe was characterized by a ridge, with its axis located over Germany (R7 in Fig. 9a). Upstream, a wave pattern featured troughs over the eastern North Pacific, the eastern United States and trough T7 over the eastern North Atlantic as well as ridges over the western United States and the western North Atlantic (Fig. 9a). Collocated with the European ridge (R7), hot spell durations of 1-5 days were identified from western France all the way to the Baltic states (Fig. 6b), while over western North America and the western North Atlantic hot spells had been initiated already multiple days earlier (Fig. 6b). By 27 July, a new Rossby wave packet had formed a trough-ridge couple (T8, R8) over Europe, in phase with the previous one and reamplified the temperature anomaly pattern (Figs. 9c,d). Over northern 

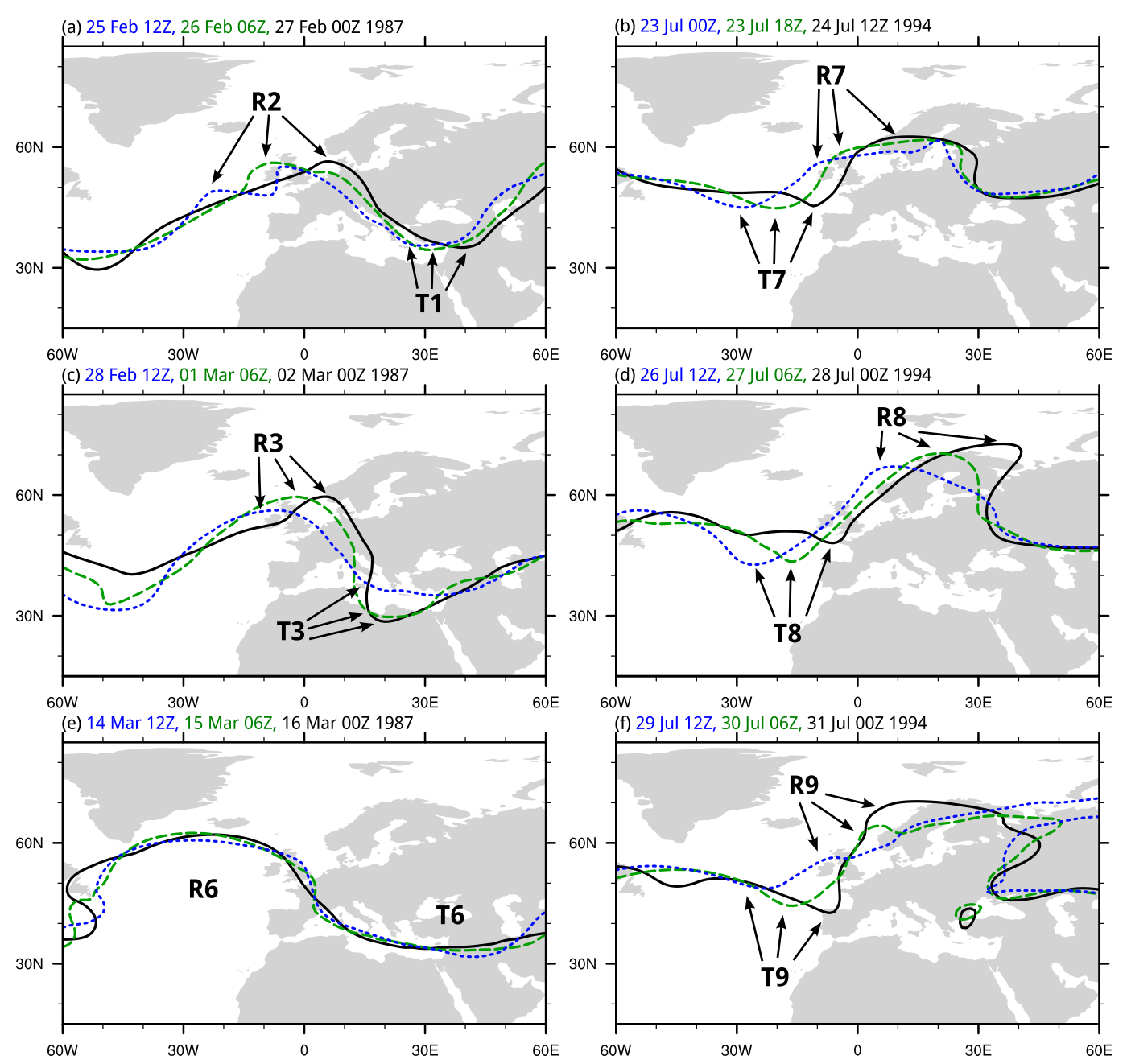

FIG. 7. (a),(c),(e) Position of the $10200 \mathrm{~m}$ geopotential height contour on $250 \mathrm{hPa}$ at the dates indicated at the top left of each panel. (b),(d),(f) Position of the $10600 \mathrm{~m}$ geopotential height contour on $250 \mathrm{hPa}$ at the dates indicated at the top left of each panel. The black contour is valid at the last date in each panel while the light (heavy) dashed blue (green) contour indicates the contour position $36(18) \mathrm{h}$ prior to the last date of each panel. Labels and arrows indicate the progression of the peaks of the respective troughs and ridges.

Europe blocking was detected by the Schwierz et al. (2004) index (Fig. 9d). During the next 9 days, two additional trough-ridge couplets (T9, R9 and T10, R10) amplified over the eastern North Atlantic and Europe (Figs. 9e,g) and further prolonged the duration of hot spells in Europe. By 5 August, hot spells in Poland persisted for up to two weeks (Fig. 6h). At the same time, a block formed over the western North Atlantic (Fig. 8c, 9h). Downstream of this block, colder air reached central Europe on 8 August (not shown) and terminated the hot spells north of the Alps by 10 August (Fig. 6j), while in southern Europe anomalously warm temperatures persisted several days longer (not shown).

Interestingly, also for this summer case, with conceivably a weaker background flow than the February-
March 1987 case, the synoptic-scale waves building up this RRWP are not stationary, in particular not over Europe (Fig. 8a). The propagation of troughs T7-T9 and ridges $\mathrm{R} 7-\mathrm{R} 9$ is illustrated in Fig. 7b,d,f and clearly shows that also in this case the recurrent amplification of transient and nonstationary troughs and ridges helped to generate these long-lasting hot spells over Europe.

In summary, both cases discussed in this section clearly illustrate that RRWPs, built up by synoptic-scale wave packets, can trigger unusually persistent cold and hot spells simultaneously in multiple large regions separated by roughly one synoptic wavelength. Hereby synoptic-scale troughs and ridges repeatedly amplify at the same longitudes and generate the persistent synoptic-wavenumber signal in the Hovmöller diagram. 

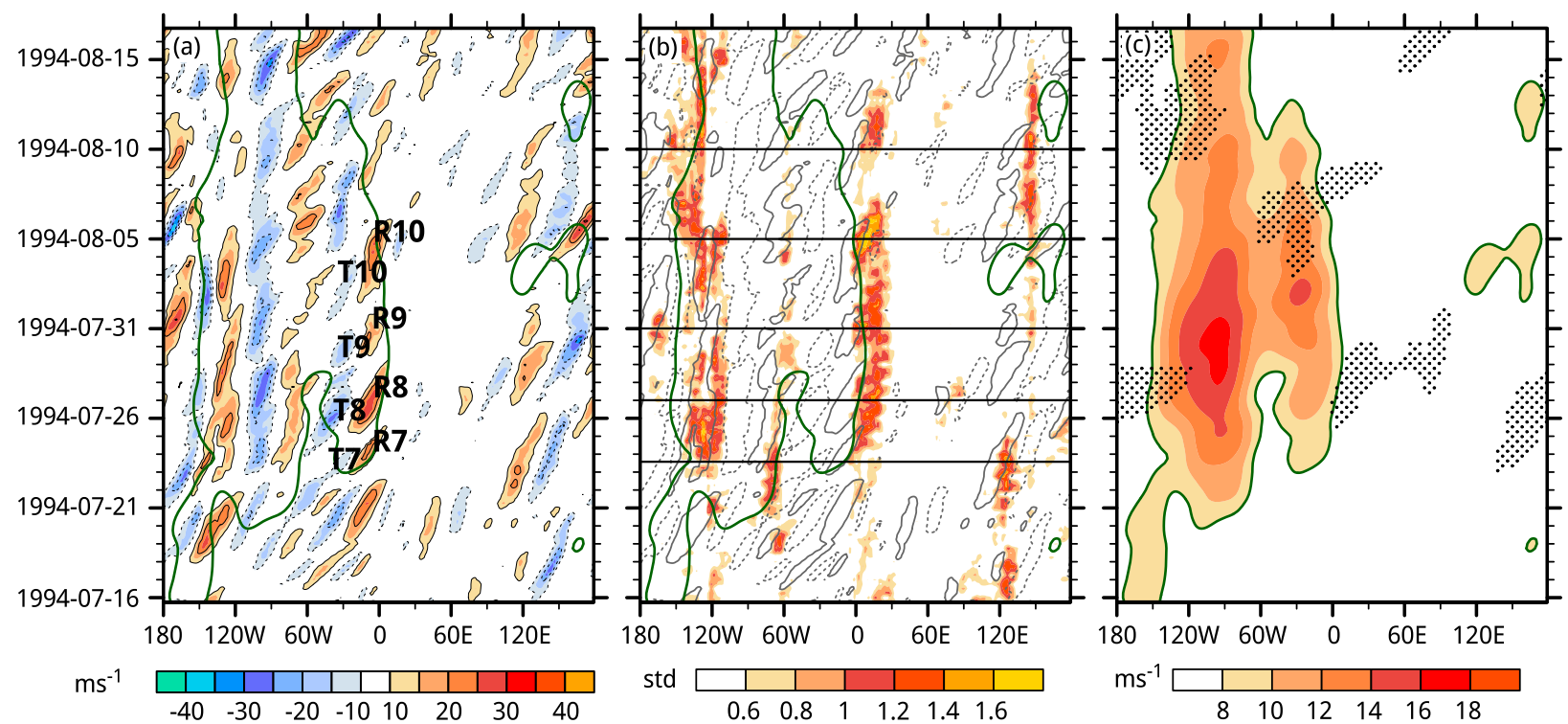

FIG. 8. Hovmöller diagrams of (a) $v_{\mathrm{ma}}$ at $250 \mathrm{hPa}$, (b) standardized 2-m temperature anomaly averaged between $35^{\circ}$ and $65^{\circ} \mathrm{N}$, and (c) $R$ (shading, note the slightly different color bar compared to Fig. 4c) for the RRWP in summer 1994. Troughs T7-T10 and ridges R7-R10 are indicated in (a). Horizontal lines in (b) indicate times for which fields are shown in Fig. 9. Dashed (solid) gray lines in (b) indicate $v_{\text {ma }}(\lambda, t)$ at $250 \mathrm{hPa}$ of $-10(10) \mathrm{m} \mathrm{s}^{-1}$. Dotted areas in (c) show at which longitudes and times blocking is detected at least at one grid point between $0^{\circ}$ and $90^{\circ} \mathrm{N}$. The green solid contour in all panels shows $R=8 \mathrm{~m} \mathrm{~s}^{-1}$.

Moreover, during both cases atmospheric blocking occurred, but not continuously during the entire periods and at various different locations relative to the RRWPs (Figs. 4c, 8c).

\section{Climatological effect of RRWPs on the duration of cold and hot spells}

In this section, we assess the climatological impact of RRWPs on the duration of cold and hot spells by means of the Weibull regression model introduced in section 2e. Figures 10a and 10b show the acceleration factors $\exp \left(\alpha_{1}\right)$ for NDJFMA cold spells and MJJASO hot spells, respectively. Recall that the Weibull regression model in Eq. (3) is constructed such that $\exp \left(\alpha_{1}\right)$ shows the factor of change in all quantiles of the (predicted) spell durations $D$ per unit $\left(\mathrm{m} \mathrm{s}^{-1}\right)$ increase in $\tilde{R}$ (see also supplemental material). However, here we do not use Eq. (3) to predict the distribution of $D$ for a given level of $\tilde{R}$ and the exact values of $\exp \left(\alpha_{1}\right)$ are thus not of primary importance. Instead, we focus on the spatial pattern of the statistically significant $\exp \left(\alpha_{1}\right)$ values as well as the sign of $\alpha_{1}$ : at grid points with $\exp \left(\alpha_{1}\right)>1$ $\left[\exp \left(\alpha_{1}\right)<1\right]$ the spell durations become longer (shorter) with increasing $\tilde{R}$ values.

Figure 10a shows that almost all statistically significant acceleration factors for cold spells are larger than 1 and thus indicate regions where RRWP conditions lead to increased cold spell durations. Acceleration factors larger than 1 primarily occur in five regions: the central North Pacific, the U.S. West Coast, the U.S. East Coast, and the western Atlantic as well as the Mediterranean (Fig. 10a). Acceleration factors statistically significantly smaller than 1 are found in the northwestern North Atlantic and the northwestern North Pacific, mostly north of $50^{\circ} \mathrm{N}$ (Fig. 10a). In these regions RRWP conditions lead to shorter-than-normal cold spell durations.

In vast areas of the Northern Hemisphere midlatitudes and subtropics, NDJFMA cold spells thus tend to be longer during collocated RRWPs. However, the positive effect of RRWPs on the duration of cold spells is confined to areas south of $50^{\circ} \mathrm{N}$. This result seems plausible, as at these latitudes temperature advection is key for generating cold conditions (Screen 2014; Bieli et al. 2015), which requires the meridional transport of air masses and thus an amplified flow pattern. Particularly persistent cold spells then occur if the amplified flow pattern remains in the same phase for longer than normal periods, for example, during RRWPs.

The reduction in cold spell durations during collocated RRWPs over the northwestern North Atlantic and northwestern North Pacific can be understood by considering the locations of these regions relative to the climatologically strongest surface baroclinicity over the western North Atlantic and western North Pacific. A highly amplified flow pattern (e.g., an RRWP) over the northwestern North Atlantic or the northwestern North Pacific conceivably results in increased meridional 

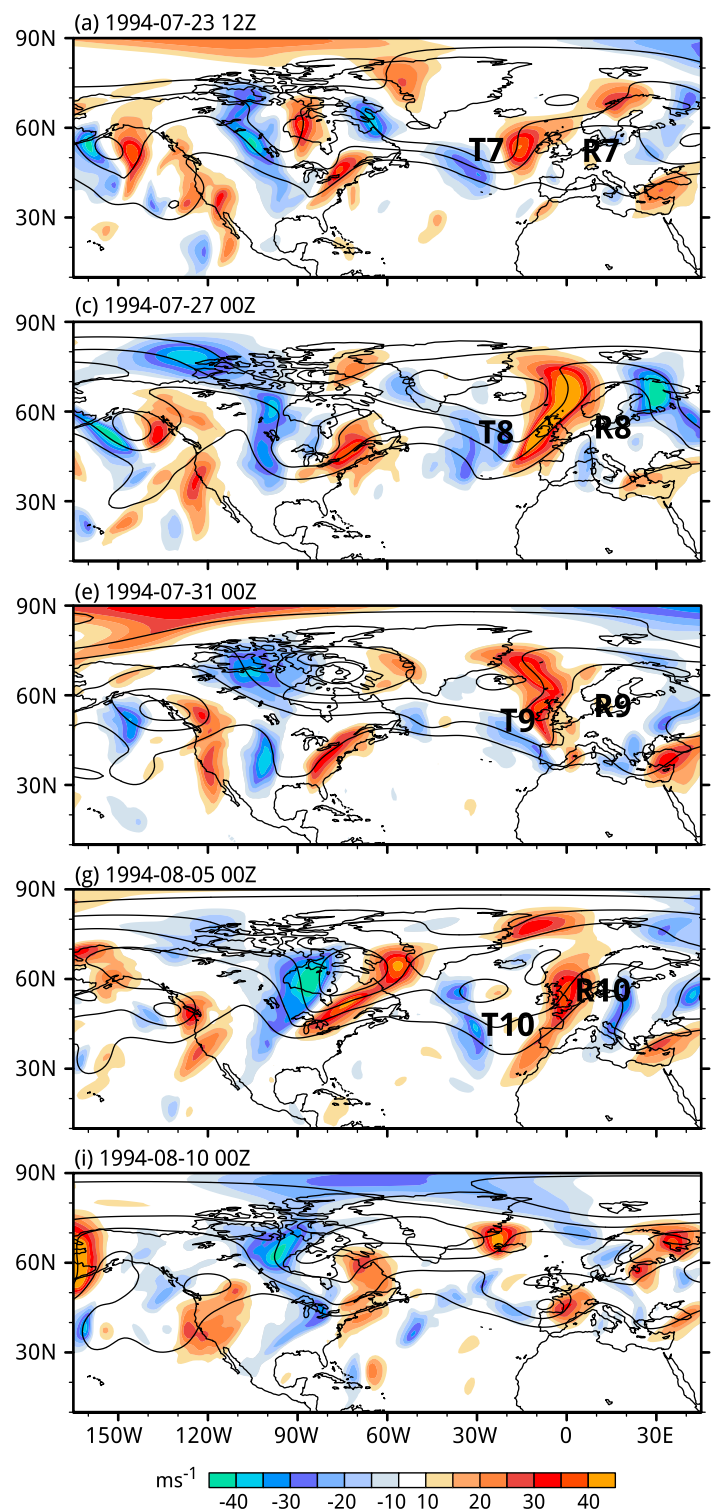

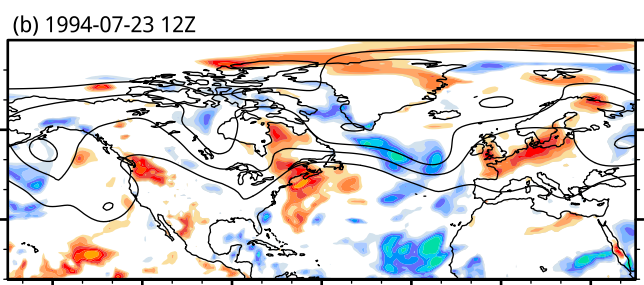

(d) 1994-07-27 00Z

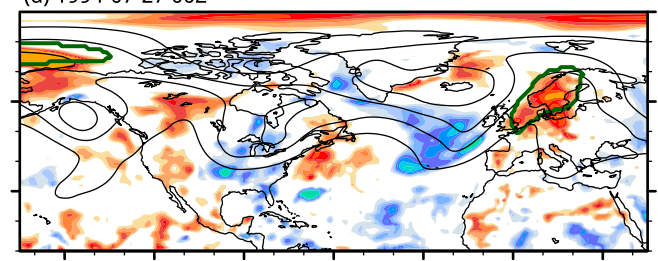

(f) 1994-07-31 00Z

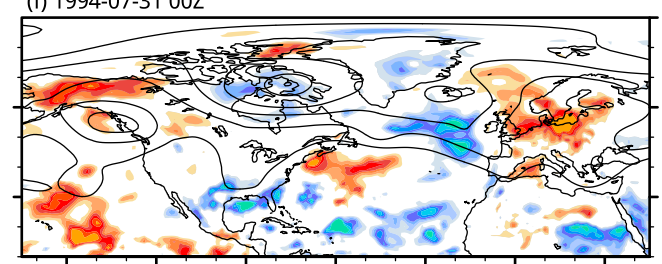

(h) $1994-08-0500 Z$
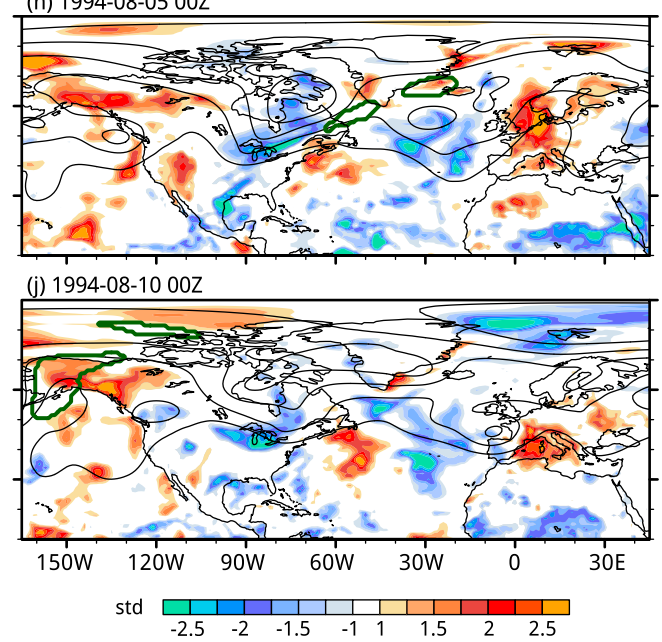

FIG. 9. (a),(c),(e),(g),(i) Meridional wind $v$ at $250 \mathrm{hPa}$ (shading), and (b),(d),(f),(h),(j) standardized 2-m temperature anomaly (shading). Black contours indicate 250-hPa geopotential height starting from 9800 to $10800 \mathrm{~m}$ in steps of $200 \mathrm{~m}$. Green contours in (b),(d),(f),(h),(j) show atmospheric blocking as defined in Schwierz et al. (2004). The positions of the troughs T7-T10 and ridges R7-R10 are indicated in panels (a),(c),(e),(g),(i).

transport of sensible heat into the respective area of smaller $\exp \left(\alpha_{1}\right)$ and thus shortens cold spells there, if they form at all.

Summer hot spells are more persistent during collocated RRWPs in numerous and widespread areas of the Northern Hemisphere midlatitudes (Fig. 10b). In contrast to cold spells, the pattern of statistically significant $\exp \left(\alpha_{1}\right)$ shows a clear zonal wave structure (approximately wavenumber 6-7). Over land, hot spell durations over western North America, western Europe, western Russia, and central Asia are particularly sensitive to
RRWPs. The fact that the $\exp \left(\alpha_{1}\right)$ pattern exhibits this wave structure indicates that the phasing and zonal wavenumber of the waves during summer RRWPs is not arbitrary, but that a particular wavenumber-6-7 pattern is preferred.

Moreover, the patterns shown in Fig. 10 also clearly differ from the climatological distribution of blocking, which typically exhibits three to four maxima, centered over the Gulf of Alaska, Greenland, Scandinavia, and, for some blocking indices, over western Russia (CrociMaspoli et al. 2007; Masato et al. 2013; Barnes et al. 

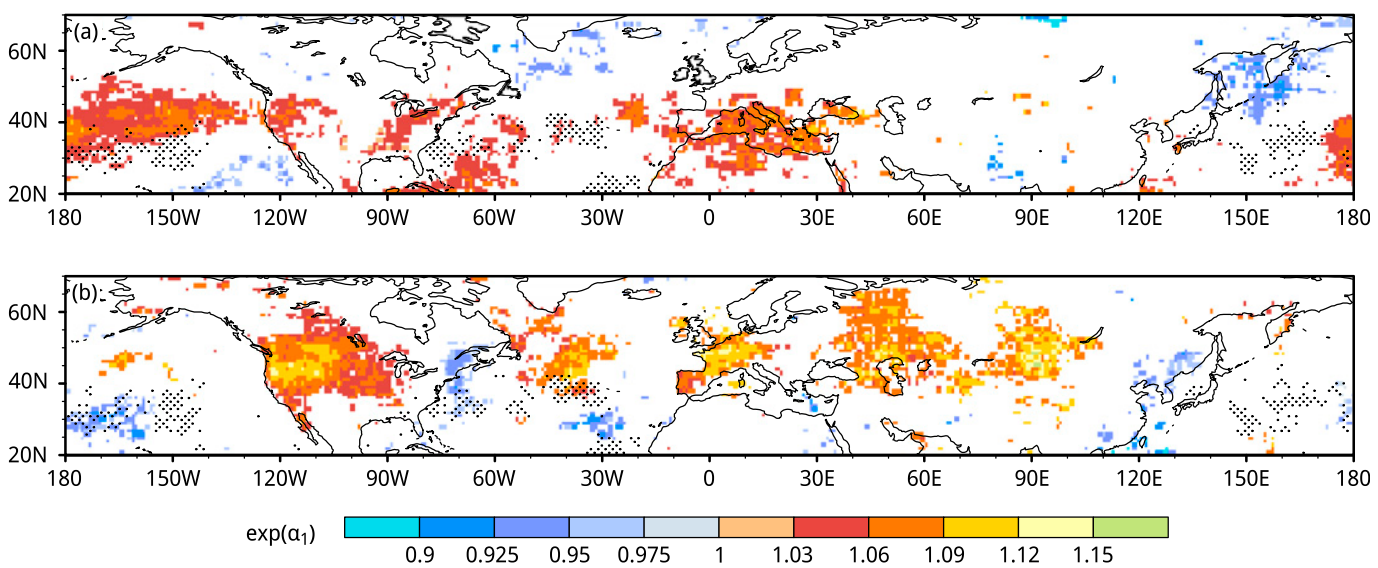

FIG. 10. Acceleration factors $\exp \left(\alpha_{1}\right)$ for (a) NDJFMA cold spells and (b) MJJASO hot spells. Only statistically significant acceleration factors are shown. Stippling denotes areas where the Anderson-Darling test rejects the null hypothesis that the spell durations follow a Weibull distribution at the $p<0.01$ significance level.

2014). This difference, as well as the case studies presented here, suggests that RRWPs and blocking are dynamically different but conceivably related phenomena that both foster persistent high-impact surface weather. The relationship between RRWPs and atmospheric blocking is therefore of interest and is the topic of the next section.

\section{Co-occurrence of atmospheric blocking and RRWPs}

As both RRWPs and blocking are associated with particularly persistent surface weather, it is conceivable that they often co-occur. Figure 11 depicts three possible types of co-occurrence of blocking and RRWPs. It has long been recognized that synoptic-scale waves often amplify upstream of blocking anticyclones, thereby reinforcing the block and contributing to its persistence (e.g., Berggren et al. 1949; Shutts 1983). Moreover, Röthlisberger et al. (2018) have shown that synopticscale Rossby waves are often initiated upstream of a preexisting stationary ridge. Climatologically, blocking onset over both the North Pacific and North Atlantic is therefore preceded by a precursor wave train upstream (Altenhoff et al. 2008). Thus, it is plausible that waves amplifying repeatedly at the same longitude and leading to RRWP conditions also foster blocking further downstream of the amplifying waves (Fig. 11a). To verify this hypothesis, Fig. 12 shows Hovmöller composites of $R$ anomalies, centered on the mean longitude and time of (a)

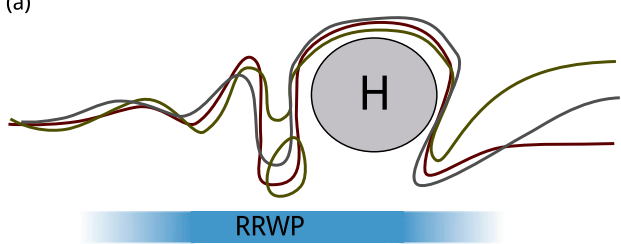

(b)

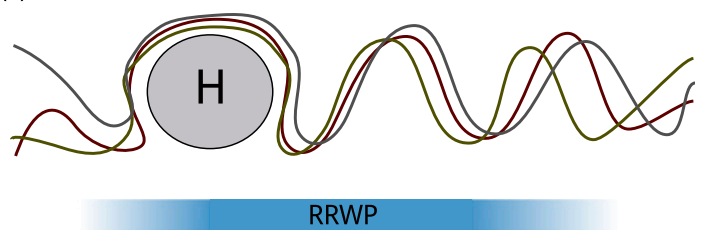

(c)

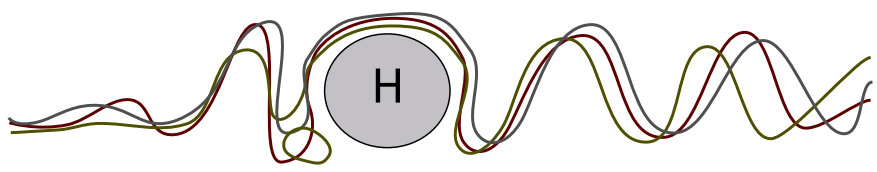

RRWP

FIG. 11. Schematic of three types of co-occurrence of blocking and RRWPs: (a) blocking at the downstream end of an RRWP, resulting from waves amplifying at similar longitudes; (b) blocking acting similar to a metronome for the phasing of the waves downstream; (c) combination of (a) and (b). Gray, brown, and green lines indicate the shape of the midlatitude jet for three instances in time during a particular RRWP. The blocking anticyclone is depicted as a gray ellipse. The approximate longitudinal extent of the RRWP is indicated with the blue bar. 

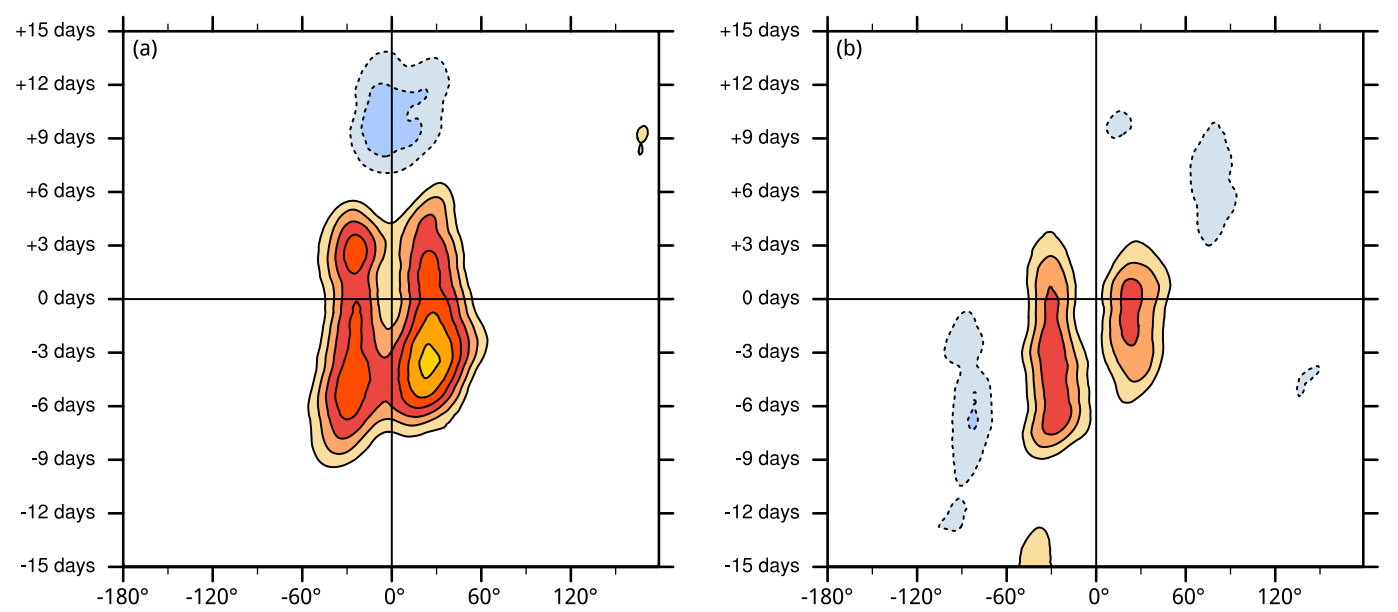

$\mathrm{ms}^{-1}$

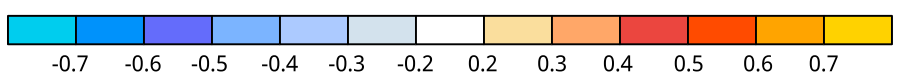

FIG. 12. Hovmöller composites of $R$ anomalies centered on the mean longitude and time of maximum amplitude of (a) North Pacific (mean location at time of maximum amplitude in $30^{\circ}-80^{\circ} \mathrm{N}, 110^{\circ} \mathrm{E}-110^{\circ} \mathrm{W}$ ) and (b) North Atlantic $\left(30^{\circ}-80^{\circ} \mathrm{N}, 90^{\circ} \mathrm{W}-50^{\circ} \mathrm{E}\right)$ blocks. Anomalies are calculated with respect to the climatology shown in Fig. $3 \mathrm{a}$.

maximum amplitude of North Pacific (Fig. 12a) and North Atlantic (Fig. 12b) blocks. The $R$ anomalies have been calculated relative to the climatology shown in Fig. 3a and North Pacific and North Atlantic blocks have been identified in the same regions as in Altenhoff et al. (2008) (geographical center at time of maximum amplitude in $30^{\circ}-80^{\circ} \mathrm{N}, 110^{\circ} \mathrm{E}-110^{\circ} \mathrm{W}$ and $30^{\circ}-80^{\circ} \mathrm{N}$, $90^{\circ} \mathrm{W}-50^{\circ} \mathrm{E}$, respectively). For both North Pacific and North Atlantic blocking, $R$ is increased upstream of the block, in particular 3-9 days prior to the time of maximum amplitude of the blocks (Fig. 12). As the blocks identified with the Schwierz et al. (2004) algorithm have a mean lifetime of only seven days (Croci-Maspoli 2005), RRWPs also seem to act as precursor to blocking onset.

Moreover, Altenhoff et al. (2008) have shown that, climatologically, a wave train often extends downstream from mature blocking events, especially for blocking events over the North Pacific. Downstream of a blocking anticyclone, one could expect troughs to form repeatedly at similar longitudes. It is therefore plausible that blocking, because of its stationarity, can act similarly to a metronome for the midlatitude Rossby waves downstream, leading to RRWP conditions there (Fig. 11b). Indeed, $R$ values are increased downstream of both North Pacific and North Atlantic blocks for at least one synoptic wavelength. This signal is particularly pronounced for North Pacific blocks 3-6 days prior to the time of maximum amplitude of the blocks (Fig. 12a). This result suggests that in particular during the early stages in the life cycle of North Pacific blocks, RRWPs often form downstream of the block. Finally, it is conceivable that in some cases also a combination of the two mechanisms occurs (Fig. 11c).

Interestingly, though, $R$ is not increased considerably at the location of the block during the time of maximum amplitude. We hypothesize that this is because the upper-level ridges associated with blocks tend to be generally wider than the troughs upstream and downstream of the blocks (e.g., Wolf and Wirth 2015). Thus, the wavelength of the ridge associated with the block itself might be too large to be captured by the metric $R$, and hence no positive anomalies of $R$ collocated with the blocks appear in Fig. 12.

\section{Summary and open questions}

In this study we introduce the concept of recurrent Rossby wave patterns (RRWPs) and discuss their effect on the persistence of cold and hot spells. An RRWP is a sequence of synoptic-scale transient Rossby wave packets, each of which covers several synoptic wavelengths in the same phase as the other wave packets. Thereby, synoptic-scale troughs and ridges repeatedly amplify at the same longitude. We illustrate the effect of RRWPs on cold and hot spells based on two case studies in February-March 1987 and in July-August 1994, which led to unusually persistent cold and hot spells, respectively. Hereby, we find that RRWPs can lead to persistent high-impact weather simultaneously over several synoptic wavelengths.

A metric termed $R$ is then introduced to identify RRWP conditions in Hovmöller diagrams of the 250$\mathrm{hPa}$ meridional wind. First, a 14.25-day running mean is 
applied to the Hovmöller diagram to filter for signals lasting longer than typical synoptic time scales. The metric $R$ is then calculated as the envelope of the synoptic wavenumber (4-15) signal in the time-filtered Hovmöller diagram. Inspection of $R$-Hovmöller diagrams during the RRWP cases described in Davies (2015) and Barton et al. (2016), as well as many additional cases including the RRWPs in February-March 1987 and July-August 1994, indicates that $R$ quite reliably identifies RRWP conditions.

The metric $R$ is then used to quantify the climatological effect of RRWPs on November-April cold spells and May-October hot spells. At each grid point between $20^{\circ}$ and $70^{\circ} \mathrm{N}$ we fit a Weibull regression model to cold and hot spell durations and include a measure of $R(\tilde{R})$ as a covariate for the spell durations $D$. This statistical analysis in combination with prior knowledge of the effect of synoptic-scale Rossby wave packets on surface temperature makes it possible to assess where RRWPs significantly affect the spell duration distribution. The pattern of the exponentiated regression coefficients for $\tilde{R}\left[\exp \left(\alpha_{1}\right)\right]$ reveals a positive and statistically significant influence of RRWPs (as characterized by $\tilde{R}$ ) on the duration of NDJFMA cold spells in vast areas of the Northern Hemisphere midlatitudes and subtropics. Areas where RRWPs statistically significantly lengthen cold spells include the U.S. West and East Coasts, the Mediterranean, and the central North Pacific.

The pattern of $\exp \left(\alpha_{1}\right)$ for MJJASO hot spells also reveals large areas where RRWPs are associated with longer-lasting hot spells. The areas of $\exp \left(\alpha_{1}\right)>1$ are each separated by roughly one synoptic wavelength and exhibit a clear zonal wave pattern. Over land, largest values of $\exp \left(\alpha_{1}\right)$ are found in western North America, western Europe, western Russia, and central Asia. The fact that the $\exp \left(\alpha_{1}\right)$ field exhibits this wave pattern indicates that in extended summer, RRWPs tend to occur in a preferred phase and preferentially with a wavenumber-6-7 pattern.

We further discussed the relationship between atmospheric blocking and RRWPs. RRWPs can trigger persistent surface weather over multiple synoptic wavelengths, while blocking fosters persistent weather within one synoptic wavelength of the block itself (Buehler et al. 2011; Pfahl and Wernli 2012; Whan et al. 2016). RRWPs and blocking should therefore be considered as dynamically distinct but conceivably related phenomena. Hovmöller composites of $R$ relative to the mean longitude and time of maximum amplitude of blocking events reveal that $R$ is increased both upstream and downstream of mature atmospheric blocking. This result is consistent with the result of several studies on the link between synoptic-scale Rossby waves and blocking (e.g., Berggren et al. 1949; Shutts 1983; Altenhoff et al. 2008) and suggests the following three types of co-occurrences of atmospheric blocking and RRWPs: 1) Waves amplifying in the same phase upstream of the block continuously reinforce the block and lead to RRWP conditions upstream of the block. 2) Blocking acting similar to a metronome to the midlatitude waves and leading to RRWP conditions downstream of the block. 3) Combining types 1 and 2 leads to an RRWP extending on either side of a block.

The conclusions drawn from this study are somewhat limited by three factors. First, conventional Hovmöller diagrams do not always accurately depict midlatitude Rossby wave packets over their entire lifetimes, especially in situations where multiple waveguides occur at the same longitude and within the latitudinal band used for the construction of the Hovmöller diagram (Martius et al. 2006; Glatt et al. 2011; Glatt and Wirth 2014). Therefore, more sophisticated tools for identifying and tracking Rossby wave packets have recently been developed (Glatt and Wirth 2014; Souders et al. 2014a; Grazzini and Vitart 2015; Wolf and Wirth 2017; Wirth et al. 2018). Even though the conventional Hovmöller diagram may occasionally underestimate the amplitude and propagation distance of a particular Rossby wave packet (Glatt et al. 2011), it is able to correctly represent the phasing of the wave packets wherever they are visible in the conventional Hovmöller diagram. Therefore, the shortcomings of the conventional Hovmöller diagram do not jeopardize the results and conclusions presented here. Rather, even clearer results might perhaps be achievable by considering more sophisticated ways to identify synoptic-scale Rossby wave packets. Second, the simple RRWP metric $R$ can contain contributions from persistent stationary hemispheric wave patterns; however, clear longitudinally confined maxima in the $R$ climatology suggest that $R$ is mostly affected by recurrent synoptic-scale Rossby wave packets rather than persistent stationary hemispheric wave patterns. Third, the Weibull regression model has a tendency to underestimate extremely long spell durations and the model fit is therefore not perfect (see supplemental material). Here, however, we only use the statistical model to assess where RRWPs have a significant influence on the spell durations and find that such an influence in large areas of the Northern Hemisphere midlatitudes, even with the underestimation of the longest spell durations. Therefore, we consider the $\exp \left(\alpha_{1}\right)$ patterns shown in Fig. 10 as a robust result (see also supplemental material).

Overall, the demonstrated direct effect of RRWPs on the persistence of cold and hot spells suggests that RRWPs should be studied more intensively than has 
hitherto been the case. Here, we have restricted ourselves to describing RRWPs and their effect on cold and hot spell durations; however, we have not thoroughly addressed the question of what causes RRWPs. Atmospheric blocking is a plausible candidate, but other factors such as Rossby wave forcing from the tropics, stratospheric dynamics, soil-moisture anomalies, midlatitude sea surface temperature anomalies, orography, or wave-mean flow interactions might be important as well. Moreover, the RRWP in July-August 1994 coincides with one of the quasi-resonance periods identified by Kornhuber et al. (2017), which raises the question of how RRWPs and quasi-resonance periods might be related. Future research will therefore investigate the dynamical causes of RRWPs and will also include a comparison between RRWP events and quasiresonance periods. Moreover, RRWPs occur on a time scale of several weeks, and therefore also merit consideration from a subseasonal forecasting perspective. Finally, the recent vivid scientific discussion on potentially changing persistent high-impact weather with climate change motivates an investigation of RRWPs in future climate simulations.

Acknowledgments. MR would like to thank Huw C. Davies (ETH Zurich), Ryan Torn (SUNY Albany), and Christoph Dätwyler (University of Bern) for valuable comments during different stages of this work. Moreover, the two reviewers are acknowledged for their thoughtful and encouraging reviews. Furthermore, MR acknowledges the Swiss National Science foundation for funding (Grant 200021_159905/1), and LFB and DK acknowledge the U.S. National Science Foundation for funding (Grant AGS-1355960). The authors declare no conflicts of interests.

\section{REFERENCES}

Altenhoff, A. M., O. Martius, M. Croci-Maspoli, C. Schwierz, and H. C. Davies, 2008: Linkage of atmospheric blocks and synoptic-scale Rossby waves: A climatological analysis. Tellus, 60A, 1053-1063, https://doi.org/10.1111/j.1600-0870.2008.00354.x.

Barnes, E. A., 2013: Revisiting the evidence linking Arctic amplification to extreme weather in midlatitudes. Geophys. Res. Lett., 40, 4734-4739, https://doi.org/10.1002/ grl.50880.

— ploring recent trends in Northern Hemisphere blocking. $\mathrm{Ge}$ ophys. Res. Lett., 41, 638-644, https://doi.org/10.1002/ 2013 GL058745.

Barriopedro, D., E. Fischer, J. Luterbacher, R. Trigo, and G.-H. Ricardo, 2011: The hot summer of 2010: Redrawing the temperature record map of Europe. Science, 332, 220-224, https:// doi.org/10.1126/science.1201224.

Barton, Y., P. Giannakaki, H. von Waldow, C. Chevalier, S. Pfahl, and O. Martius, 2016: Clustering of regional-scale extreme precipitation events in southern Switzerland. Mon. Wea. Rev., 144, 347-369, https://doi.org/10.1175/MWR-D-15-0205.1.

Benjamini, Y., and Y. Hochberg, 1995: Controlling the false discovery rate: A practical and powerful approach to multiple testing. J. Roy. Stat. Soc., 57, 289-300.

Berggren, R., B. Bolin, and C.-G. Rossby, 1949: An aerological study of zonal motion, its perturbations and break-down. Tellus, 1 (2), 14-37, https://doi.org/10.3402/tellusa.v1i2.8501.

Bieli, M., S. Pfahl, and H. Wernli, 2015: A Lagrangian investigation of hot and cold temperature extremes in Europe. Quart. J. Roy. Meteor. Soc., 141, 98-108, https://doi.org/10.1002/qj.2339.

Black, E., M. Blackburn, R. G. Harrison, B. J. Hoskins, and J. Methven, 2004: Factors contributing to the summer 2003 European heatwave. Weather, 59 (8), 217-223, https://doi.org/ 10.1256/wea.74.04.

Buehler, T., C. C. Raible, and T. F. Stocker, 2011: The relationship of winter season North Atlantic blocking frequencies to extreme cold or dry spells in the ERA-40. Tellus, 63A , 212-222, https://doi.org/10.1111/j.1600-0870.2010.00492.x.

Chang, E. K. M., and D. B. Yu, 1999: Characteristics of wave packets in the upper troposphere. Part I: Northern Hemisphere winter. J. Atmos. Sci., 56, 1708-1728, https://doi.org/ 10.1175/1520-0469(1999)056<1708:COWPIT>2.0.CO;2.

Cohen, J., and Coauthors, 2014: Recent Arctic amplification and extreme mid-latitude weather. Nat. Geosci., 7, 627-637, https://doi.org/10.1038/ngeo2234.

Coumou, D., V. Petoukhov, S. Rahmstorf, S. Petri, and H. J. Schellnhuber, 2014: Quasi-resonant circulation regimes and hemispheric synchronization of extreme weather in boreal summer. Proc. Natl. Acad. Sci. USA, 111, 12 331-12 336, https://doi.org/10.1073/pnas.1412797111.

Croci-Maspoli, M., 2005: Climatological investigations of atmospheric blocking-A dynamically-based statistical analysis. Dissertation, ETH Zürich, 115 pp.

_ C. Schwierz, and H. C. Davies, 2007: A multifaceted climatology of atmospheric blocking and its recent linear trend. J. Climate, 20, 633-649, https://doi.org/10.1175/JCLI4029.1.

Davies, H. C., 2015: Weather chains during the 2013/2014 winter and their significance for seasonal prediction. Nat. Geosci., $\mathbf{8}$, 833-837, https://doi.org/10.1038/ngeo2561.

Dee, D. P., and Coauthors, 2011: The ERA-Interim reanalysis: Configuration and performance of the data assimilation system. Quart. J. Roy. Meteor. Soc., 137, 553-597, https://doi.org/ 10.1002/qj.828.

Dole, R., and Coauthors, 2011: Was there a basis for anticipating the 2010 Russian heat wave? Geophys. Res. Lett., 38, L06702, https://doi.org/10.1029/2010GL046582.

Fragkoulidis, G., V. Wirth, P. Bossmann, and A. H. Fink, 2018: Linking Northern Hemisphere temperature extremes to Rossby wave packets. Quart. J. Roy. Meteor. Soc., 144, 553566, https://doi.org/10.1002/qj.3228.

Francis, J. A., and N. Skific, 2015: Evidence linking rapid Arctic warming to mid-latitude weather patterns. Philos. Trans. Roy. Soc. London, 373A, 20140170, https://doi.org/10.1098/rsta.2014.0170.

_ to extreme weather in mid-latitudes. Geophys. Res. Lett., 39 , L06801, https://doi.org/10.1029/2012GL051000.

$\longrightarrow$, and — 2015: Evidence for a wavier jet stream in response to rapid Arctic warming. Environ. Res. Lett., 10, 014005, https://doi.org/10.1088/1748-9326/10/1/014005.

Glatt, I., and V. Wirth, 2014: Identifying Rossby wave trains and quantifying their properties. Quart. J. Roy. Meteor. Soc., 140, 384-396, https://doi.org/10.1002/qj.2139. 
— A. Dörnbrack, S. Jones, J. Keller, O. Martius, A. Müller, D. H. W. Peters, and V. Wirth, 2011: Utility of Hovmöller diagrams to diagnose Rossby wave trains. Tellus, 63A, 9911006, https://doi.org/10.1111/j.1600-0870.2011.00541.x.

Grazzini, F., and F. Vitart, 2015: Atmospheric predictability and Rossby wave packets. Quart. J. Roy. Meteor. Soc., 141, 2793 2802, https://doi.org/10.1002/qj.2564.

Hassanzadeh, P., Z. Kuang, and B. F. Farrell, 2014: Responses of midlatitude blocks and wave amplitude to changes in the meridional temperature gradient in an idealized dry GCM. Geophys. Res. Lett., 41, 5223-5232, https://doi.org/10.1002/ 2014 GL060764.

Horton, D. E., N. C. Johnson, D. Singh, D. L. Swain, B. Rajaratnam, and N. S. Diffenbaugh, 2015: Contribution of changes in atmospheric circulation patterns to extreme temperature trends. Nature, 522, 465-469, https://doi.org/10.1038/ nature 14550.

Hoskins, B. J., and T. Ambrizzi, 1993: Rossby wave propagation on a realistic longitudinally varying flow. J. Atmos. Sci., $\mathbf{5 0}$, 1661-1671, https://doi.org/10.1175/1520-0469(1993)050<1661: RWPOAR $>2.0 . \mathrm{CO} ; 2$.

_ , and T. Woollings, 2015: Persistent extratropical regimes and climate extremes. Curr. Climate Change Rep., 1, 115-124, https://doi.org/10.1007/s40641-015-0020-8.

_ M. E. McIntyre, and A. W. Robertson, 1985: On the use and significance of isentropic potential vorticity maps. Quart. J. Roy. Meteor. Soc., 111, 877-946, https://doi.org/10.1002/ qj. 49711147002.

Hosmer, D. W., S. Lemeshow, and S. May, 2008: Applied Survival Analysis. 2nd ed., Wiley Series in Probability and Statistics, John Wiley \& Sons, 416 pp., https://doi.org/10.1002/9780470258019.

Hovmöller, E., 1949: The trough-and-ridge diagram. Tellus, 1, 62 66, https://doi.org/10.3402/tellusa.v1i2.8498.

Kleinbaum, D. G., and M. Klein, 2012: Survival Analysis: A SelfLearning Text. 3rd ed. Springer, 520 pp., https://doi.org/ 10.1007/978-1-4419-6646-9.

Kornhuber, K., V. Petoukhov, S. Petri, S. Rahmstorf, and D. Coumou, 2017: Evidence for wave resonance as a key mechanism for generating high-amplitude quasi-stationary waves in boreal summer. Climate Dyn., 49, 1961-1979, https:// doi.org/10.1007/s00382-016-3399-6.

Lee, S., and I. M. Held, 1993: Baroclinic wave packets in models and observations. J. Atmos. Sci., 50,1413-1428, https://doi.org/ 10.1175/1520-0469(1993)050<1413:BWPIMA > 2.0.CO;2.

Littell, R. C., J. T. Mc Clave, and W. W. Offen, 1979: Goodness-offit tests for the two parameter Weibull distribution. Commun. Stat. Simul. Comput., 8, 257-269, https://doi.org/10.1080/ 03610917908812118.

Liu, J., J. A. Curry, H. Wang, M. Song, and R. M. Horton, 2012: Impact of declining Arctic sea ice on winter snowfall. Proc Natl. Acad. Sci. USA, 109, 4074-4079, https://doi.org/10.1073/ pnas.1114910109.

Martius, O., C. Schwierz, and H. C. Davies, 2006: A refined Hovmöller diagram. Tellus, 58A, 221-226, https://doi.org/10.1111/ j.1600-0870.2006.00172.x.

$\longrightarrow,-$, and — 2010: Tropopause-level waveguides. J. Atmos. Sci., 67, 866-879, https://doi.org/10.1175/2009JAS2995.1.

Masato, G., B. J. Hoskins, and T. Woollings, 2013: Winter and summer Northern Hemisphere blocking in CMIP5 models. J. Climate, 26, 7044-7059, https://doi.org/10.1175/ JCLI-D-12-00466.1

Palmer, T., 2014: Record-breaking winters and global climate change. Science, 344, 803-804, https://doi.org/10.1126/science.1255147.
Petoukhov, V., S. Rahmstorf, S. Petri, and H. J. Schellnhuber, 2013: Quasiresonant amplification of planetary waves and recent Northern Hemisphere weather extremes. Proc. Natl. Acad. Sci. USA, 110, 5336-5341, https://doi.org/10.1073/pnas.1222000110.

Pfahl, S., and H. Wernli, 2012: Quantifying the relevance of atmospheric blocking for co-located temperature extremes in the Northern Hemisphere on (sub-)daily time scales. Geophys. Res. Lett., 39, L12807, https://doi.org/10.1029/2012GL052261.

Pfleiderer, P., and D. Coumou, 2018: Quantification of temperature persistence over the Northern Hemisphere land-area. Climate Dyn., 51, 627-637, https://doi.org/10.1007/s00382017-3945-x.

Rohrer, M., S. Brönnimann, O. Martius, C. C. Raible, M. Wild, and G. P. Compo, 2018: Representation of extratropical cyclones, blocking anticyclones, and Alpine circulation types in multiple reanalyses and model simulations. J. Climate, 31, 3009-3031, https://doi.org/10.1175/JCLI-D-17-0350.1.

Röthlisberger, M., S. Pfahl, and O. Martius, 2016: Regional-scale jet waviness modulates the occurrence of midlatitude weather extremes. Geophys. Res. Lett., 43, 10 989-10 997, https:// doi.org/10.1002/2016GL070944.

O. Martius, and H. Wernli, 2018: Northern Hemisphere Rossby wave initiation events on the extratropical jet-A climatological analysis. J. Climate, 31, 743-760, https://doi.org/ 10.1175/JCLI-D-17-0346.1.

Russo, S., J. Sillmann, and E. M. Fischer, 2015: Top ten European heatwaves since 1950 and their occurrence in the coming decades. Environ. Res. Lett., 10, 124003, https://doi.org/10.1088/ 1748-9326/10/12/124003.

Schwierz, C., M. Croci-Maspoli, and H. C. Davies, 2004: Perspicacious indicators of atmospheric blocking. Geophys. Res. Lett., 31, L06125, https://doi.org/10.1029/2003GL019341.

Screen, J. A., 2014: Arctic amplification decreases temperature variance in northern mid- to high-latitudes. Nat. Climate Change, 4, 577-582, https://doi.org/10.1038/nclimate2268.

—, and I. Simmonds, 2013: Caution needed when linking weather extremes to amplified planetary waves. Proc. Natl. Acad. Sci. USA, 110, E2327, https://doi.org/10.1073/ pnas.1304867110.

Shutts, G. J., 1983: The propagation of eddies in diffluent jetstreams: Eddy vorticity forcing of "blocking" flow fields. Quart. J. Roy. Meteor. Soc., 109, 737-761, https://doi.org/ 10.1002/qj.49710946204.

Sillmann, J., M. Croci-Maspoli, M. Kallache, and R. W. Katz, 2011: Extreme cold winter temperatures in Europe under the influence of North Atlantic atmospheric blocking. J. Climate, 24, 5899-5913, https://doi.org/10.1175/2011JCLI4075.1.

, V. V. Kharin, X. Zhang, F. W. Zwiers, and D. Bronaugh, 2013: Climate extremes indices in the CMIP5 multimodel ensemble: Part 1. Model evaluation in the present climate. J. Geophys. Res. Atmos., 118, 1716-1733, https://doi.org/ 10.1002/jgrd.50203.

Souders, M. B., B. A. Colle, and E. K. M. Chang, 2014a: A description and evaluation of an automated approach for featurebased tracking of Rossby wave packets. Mon. Wea. Rev., 142, 3505-3527, https://doi.org/10.1175/MWR-D-13-00317.1.

,-- , and $-2014 \mathrm{~b}$ : The climatology and characteristics of Rossby wave packets using a feature-based tracking technique. Mon. Wea. Rev., 142, 3528-3548, https://doi.org/ 10.1175/MWR-D-13-00371.1.

Uppala, S. M., and Coauthors, 2005: The ERA-40 Re-Analysis. Quart. J. Roy. Meteor. Soc., 131, 2961-3012, https://doi.org/ 10.1256/qj.04.176. 
Ventura, V., C. J. Paciorek, and J. S. Risbey, 2004: Controlling the proportion of falsely rejected hypotheses when conducting multiple tests with climatological data. J. Climate, 17, 43434356, https://doi.org/10.1175/3199.1.

Whan, K., F. Zwiers, and J. Sillmann, 2016: The influence of atmospheric blocking on extreme winter minimum temperatures in North America. J. Climate, 29, 4361-4381, https:// doi.org/10.1175/JCLI-D-15-0493.1.

Wilks, D. S., 2016: "The stippling shows statistically significant grid points": How research results are routinely overstated and overinterpreted, and what to do about it. Bull. Amer. Meteor. Soc., 97, 2263-2273, https://doi.org/10.1175/BAMS-D-15-00267.1.

Wirth, V., M. Riemer, E. K. M. Chang, and O. Martius, 2018: Rossby wave packets on the midlatitude waveguide-A review. Mon. Wea. Rev., 146, 1965-2001, https://doi.org/10.1175/MWR-D-16-0483.1.
Wolf, G., and V. Wirth, 2015: Implications of the semigeostrophic nature of Rossby waves for Rossby wave packet detection. Mon. Wea. Rev., 143, 26-38, https://doi.org/10.1175/MWR-D14-00120.1.

, and —, 2017: Diagnosing the horizontal propagation of Rossby wave packets along the midlatitude waveguide. Mon. Wea. Rev., 145, 3247-3264, https://doi.org/10.1175/MWR-D16-0355.1.

Zhang, Z., 2016: Parametric regression model for survival data: Weibull regression model as an example. Ann. Transl. Med., 4, 484, https://doi.org/10.21037/atm.2016.08.45.

Zimin, A. V., I. Szunyogh, D. J. Patil, B. R. Hunt, and E. Ott, 2003: Extracting envelopes of Rossby wave packets. Mon. Wea. Rev., 131, 1011-1017, https://doi.org/10.1175/1520-0493(2003) 131<1011:EEORWP>2.0.CO;2. 